\title{
T-bet fate mapping identifies a novel ILC1-ILC2 subset in vivo
}

J-H Schroeder ${ }^{1, *}, \mathrm{~N}$ Garrido-Mesa ${ }^{1,2, *}, \mathrm{~T}$ Zabinski ${ }^{1}$, Gallagher $\mathrm{AL}^{3}$, Campbell L ${ }^{3}, \mathrm{LB}$

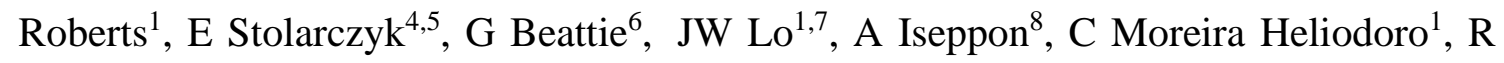

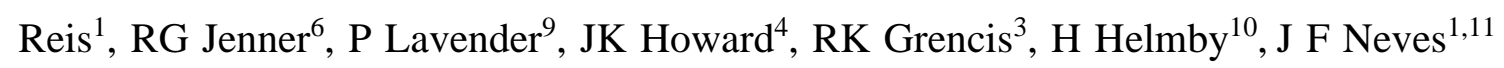
and GM Lord Lo,\#. $^{1,3,}$

\section{Affiliations:}

${ }^{1}$ Peter Gorer Department of Immunobiology, School of Immunology and Microbial Sciences, King's College London, SE1 9RT, UK

${ }^{2}$ Current address: School of Life Sciences, Pharmacy and Chemistry, Kingston University, London, KT1 2EE, UK

${ }^{3}$ Division of Infection, Immunity and Respiratory Medicine, School of Biological Sciences, Faculty of Biology, Medicine and Health, University of Manchester, M13 9PL, UK

${ }^{4}$ Department of Diabetes, School of Life Course Sciences, Faculty of Life Sciences and Medicine, King's College London, SE1 9NH, UK

${ }^{5}$ Current address: Division of Diabetes, Endocrinology and Metabolism, Imperial College London, W12 0NN, UK

${ }^{6}$ UCL Cancer Institute, University College London, London WC1E 6BT

${ }^{7}$ Current address: Division of Digestive Diseases, Faculty of Medicine, Imperial College London, W12 0NN, UK

${ }^{8}$ The Francis Crick Institute, London NW1 1AT, UK

${ }^{9} \mathrm{MRC}$ and Asthma UK Centre in Allergic Mechanisms of Asthma, King's College London, Guy's Hospital, SE1 9RT, UK 
${ }^{10}$ Department of Infection Biology, London School of Hygiene and Tropical Medicine, London WC1E 7HT, UK

${ }^{11}$ Centre for Host-Microbiome Interactions, King's College London, SE1 9RT, UK

*These authors contributed equally.

\section{\#Corresponding Author:}

Graham M Lord MD PhD FMedSci

graham.lord@manchester.ac.uk

\section{Conflict of interest statement}

The authors have declared that no conflict of interest exists.

Financial support: This study was supported by grants awarded by the Wellcome Trust (GML, 091009) and the Medical Research Council (GL, TTM, MR/M003493/1; GML, JKH, MR/K002996/1). JFN was supported by a RCUK/UKRI Rutherford Fund fellowship (MR/R024812/1). Research was also supported by the National Institute for Health Research (NIHR) Biomedical Research Centre at Guy's and St Thomas and King's College London (GL). NG was funded by Fundación Ramón Areces (Spain) and British Heart Foundation (PG/12/36/29444). The views expressed are those of the author(s) and not necessarily those of the NHS, the NIHR, or the Department of Health. 


\section{SUMMARY}

Innate lymphoid cells (ILC) play a critical role in regulating immune responses at mucosal surfaces. Three distinct ILC groups have been described according to expression of subset defining transcription factors and other markers. In this study we characterize a novel ILC subset with characteristics of group 1 and group 2 ILC in vivo. 


\begin{abstract}
Innate lymphoid cells (ILC) play a critical role in regulating immune responses at mucosal surfaces. Various subsets exist resembling T cell lineages defined by the expression of specific transcription factors. Thus, T-bet is expressed in ILC1 and Th1 cells. In order to further understand the functional roles of T-bet in ILC, we generated a fate-mapping mouse model that permanently marks cells and their progeny that are expressing, or have ever expressed T-bet. Here we have identified and characterised a novel ILC with characteristics of ILC1 and ILC2 that are "fate-mapped" for T-bet expression and arise early in neonatal life prior to establishment of a mature microbiome. These ILC1-ILC2 cells are critically dependent on T-bet and are able to express type 1 and type 2 cytokines at steady state, but not in the context of inflammation. These findings refine our understanding of ILC lineage regulation and stability and have important implications for the understanding of ILC biology at mucosal surfaces.
\end{abstract}

Keywords: T-bet; Innate lymphoid cells; ILC; intestinal inflammation; mucosal homeostasis. 


\section{INTRODUCTION}

More than 30 years ago Mosmann and Coffman provided a fundamental framework for $\mathrm{CD}^{+} \mathrm{T}$ cell biology (Mosmann and Coffman, 1989). It has now been established that the immune response of helper $\mathrm{T}$ cells can be directed to either intracellular pathogens, extracellular helminths or small extracellular pathogens (e.g. fungi or bacteria). These diverse immune responses are driven by so called type 1, 2 or 17 immune responses respectively. All of these immune responses are characterized by specific sets of cytokines. In recent years, innate lymphoid cells (ILC) have been identified as a group of lymphocytes with analogous functions to $\mathrm{CD}^{+} \mathrm{T}$ cells (reviewed by McKenzie et al., 2014). Group 1, 2 and 3 ILC (ILC1, ILC2 and ILC3) have been shown to drive a type 1, 2 or 17 immune response, respectively. Although $\mathrm{CD}^{+} \mathrm{T}$ cells and ILC have overlapping functions, there are fundamental differences. Unlike T cells, ILC do not express an antigen-specific receptor and are reliant on other signals and cells to direct their activation. These cells include antigen presenting cells, the epithelium including tuft cells, T cells and neuronal cells. Upon tissue damage the epithelium is the main provider of the ILC2-activating cytokines IL-33, IL-25 and TSLP, which together with the ILC2activating mediator TL-1A can also be secreted by various APCs (reviewed by McKenzie et al., 2014, Yu et al., 2014). CD4+ ${ }^{+}$cells can also interact with ILC2 via the TCR-MHC class II axis resulting in the enhanced proliferation of ILC2 driven by IL-2 secreted by the interacting helper T cells (Oliphant et al., 2014). Furthermore, IL-25 production by tuft cells can be triggered by succinate that appears in the gut lumen in case of microbial disbalance (Macias-Ceja et al., 2019). Several neurotransmitters have also been suggested to promote the ILC response (reviewed by Vivier et al., 2018, Klose et al., 2020). 
The presence of specific cytokines during T cell activation in secondary lymphoid organs is an important factor in polarizing helper $\mathrm{T}$ cells to Th1, Th2, Th17, Th9, Tfh or regulatory $\mathrm{T}$ cell subsets. However, these polarizations are reversible depending on the cytokines $\mathrm{CD}^{+} \mathrm{T}$ cells are being exposed to later in the tissue. This cytokine-driven phenomenon defined as plasticity has also been shown for ILC. As such, it has been observed that NKp46 ${ }^{+}$ILC3 can differentiate to ILC1 and vice versa (reviewed in Klose et al., 2020), and likewise ILC2 have shown plasticity to ILC1 and ILC3 (Bal et al., 2016, Silver et al., 2016, Ohne et al. 2016, Lim et al., 2016, Huang et al., 2015 and Zhang et al., 2018, Golebski et al., 2019). In humans and mice, IL-12 and IL-18 appear to be the most potent factors to induce T-bet and IFN- $\gamma$ in ILC2 (Bal et al., 2016, Silver et al., 2016, Ohne et al. 2016, Lim et al., 2016). Some groups have also found that IL-4 derived from eosinophils may be instrumental to convert an ILC1 to an ILC2 (Bal et al., 2016). This suggestion is interesting because ILC being predominantly resident in various mucosal organs, are likely to be in close contact with gut-resident eosinophils. It is known from studies on helper T cells that IL-4 is an important inducer of GATA3 expression (Bredo et al., 2015).

It has been shown that plasticity in $\mathrm{T}$ cells is not always absolute. $\mathrm{CD}^{+} \mathrm{T}$ cells coexpressing T-bet and ROR $\gamma \mathrm{t}$ or T-bet and GATA3 expression have been characterized (Jenner et al 2009, Affinass et al., 2018, Peine et al., 2013). NKp46 ${ }^{+}$ILC3 are known to express ROR $\gamma$ t and T-bet, but it is not known whether ILC exist that co-express GATA3 and T-bet. The existence of an ILC1-ILC2 has been predicted in RNAseq analyses using gut tissue and also from in vitro culture systems in which ILC were generated from FACS sorted human and murine ILC progenitors (Gury Ben-Ari et al., 2016, Lim et al., 2017, Xu et al., 2019). In this study we identify a heterogeneous intestinal lamina propria ILC1- 
ILC2 subset that shares characteristic expression of surface markers and transcription factors as well as functional properties usually associated with ILC2 and ILC1. These ILC1-ILC2 cells are characterised by a distinct gene expression profile and are dependent on T-bet for their development and maintenance. ILC1-ILC2 cells arise early in neonatal life before full establishment of the microbiota. Although these cells express both type 1 and type 2 cytokines at steady state, they are dispensable for anti-helminth responses in vivo and appear to be less functional during colitis. The existence of ILC1-ILC2 highlights an important novel aspect of ILC biology that should be taken into consideration in the interpretation of studies into ILC subsets. 


\section{RESULTS AND DISCUSSION}

\section{Identification of T-bet-dependent NKp46-positive intestinal ILC2}

Throughout this study we define ILC as live CD45 ${ }^{+}$Lin $^{-} \mathrm{CD} 127^{+}$(Figure 1A) and use KLRG1 as a key marker for intestinal lamina propria (LP) ILC2. NKp46 (encoded by the NCR1 gene) has been well characterized to be expressed by ILC1 and NKp46 ${ }^{+}$ILC3 (reviewed by Vivier et al., 2018). Surprisingly, we found a small population of NKp46positive colonic LP (cLP) ILC2 in ROR $\gamma \mathrm{t}$ reporter mice $\left(\mathrm{ROR} \gamma \mathrm{t}-\mathrm{eGFP} \mathrm{G}^{+-}\right.$), and $64 \%$ of these cells did not express ROR $\gamma \mathrm{t}$ (Figure 1B). NKp46 ${ }^{+}$ILC2 could also be found in C57BL/6 mice, and approximately one third of these cells expressed ST2 (Figure 1C). Interestingly, NKp46 ${ }^{+}$cLP ILC2 were not present in mice deficient for T-bet suggesting a role for T-bet in their generation or maintenance (Figure 1C-D). IFN $\gamma$ and IL-27 are known to induce T-bet expression. However, the genetic absence of either Ifng or Il27ra (wsxl) had no impact on the presence of NKp46 ${ }^{+}$cLP ILC2 (Fig 1E-F) suggesting that their roles are not critical for the generation or maintenance of these cells. As observed

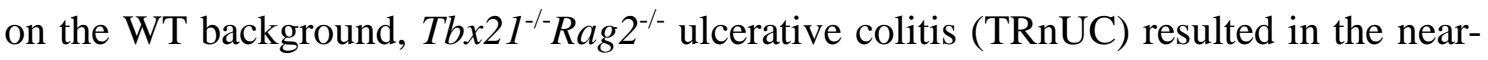
complete loss of NKp46 ${ }^{+}$cLP ILC2 (Figure 1G-H).

\section{A subset of intestinal ILC2 expresses T-bet}

Further investigations into the existence of a T-bet-dependent population of cLP ILC2 showed that a small population of CLP ILC2 were found to actively express T-bet using a T-bet reporter mouse (Figure 2A, Figure 2D). Interestingly, many but not all T-bet ${ }^{+}$ ILC2 expressed NKp46 and ST2 expression in these cells was virtually absent. T-bet expression in cLP ILC2 may be temporal and not all ILC2 may be able to induce its 
expression. In order to detect cells with a history of T-bet expression, we generated a mouse model that expresses Cre-recombinase under the expression of the T-bet endogenous promoter by inserting an IRES-Cre cassette downstream of the Tbx21 stop codon (Supplementary Figure 1A). This T-bet ${ }^{\text {Cre }}$ mouse was then bred to the Rosa26-loxstop-lox YFP mouse (Rosa26 ${ }^{\mathrm{YFP} /+}$ ) (Srinivas et al., 2001) to generate the $\mathrm{T}$ bet $^{\mathrm{Cre} / \mathrm{X}} \mathrm{x}$ Rosa $26^{\mathrm{YFP} /+}$ fate-mapper mouse (T-bet $\left.{ }^{\mathrm{FM}}\right)$. As expected, cLP ILC1 defined as

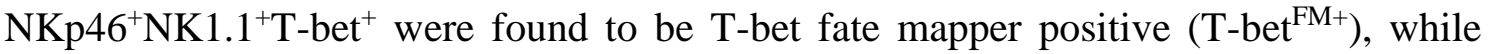
$\mathrm{CCR6}^{+}$cLP ILC did not show expression of the fate mapper (Supplementary Figure 1BC), confirming the functionality of the model - as these cells have not previously been shown to express T-bet. When examining ILC2 in these mice, we found that a subpopulation of T-bet ${ }^{\mathrm{FM}+}$ ILC2 could be found within the lamina propria in the colon, small intestine and cecum with co-expression of GATA3 (Figure 2B, Figure 2D). Interestingly, in these ILC2, T-bet-YFP expression appeared to be predominately coexpressed with low expression of GATA3, but was also found in GATA3 ${ }^{\text {hi }}$ expressing cells. In the T-bet reporter and FM model, approximately $5 \%$ of intestinal lamina propria ILC2 demonstrated T-bet expression, suggesting that the same population of cells was being detected by both models. Although T-bet is known to be expressed by two known subsets of CD127+ ILC (ILC1 and NKp46 ${ }^{+}$ILC3), it was previously less appreciated that ILC2 cells may express this transcription factor as well at steady state.

T-bet ${ }^{\mathrm{FM}+} \mathrm{ILC} 2$ defined as $\mathrm{Lin}^{-} \mathrm{CD} 127^{+} \mathrm{ICOS}^{+} \mathrm{CD} 25^{+} \mathrm{ILC}$ could further be identified in lungs and cutaneous tissue from ears, but not in the thymus (Figure 2C-D). In contrast to cutaneous T-bet ${ }^{\mathrm{FM}+}$ ILC2, pulmonary $\mathrm{T}-$-bet $^{\mathrm{FM}+}$ ILC2 predominately showed expression of ST2 and KLRG1. Induced T-bet expression in ILC2 has been reported by a number of groups. The phenomenon is best described for human blood ILC2, but Silver et al. (2016) 
have confirmed that murine pulmonary ILC2 can also express T-bet and IFN- $\gamma$ upon stimulation with IL-12 and IL-18 in vitro. However, using similar in vitro culture conditions, we were not able to induce T-bet and NKp46 expression in FACS purified cLP ILC2 from Rag2-deficient mice upon stimulation with IL-12 and IL-18 and stimulation with IL-12, IL-18 and IL-33 had no effect either (Figure 2E-F). Hence, it may be possible that plasticity in ILC2 and generation of T-bet ${ }^{+}$ILC2 may differ mechanistically depending on their tissue location.

In order to characterise the potential effector functions of $\mathrm{T}$-bet ${ }^{\mathrm{FM}+}$ cLP ILC2, we analysed their ability to express the T-bet target cytokine IFN $\gamma$ alongside IL-13, conventionally expressed by ILC2. Remarkably, these cells did express IFN $\gamma$ in contrast to conventional ILC2 while maintaining ability to express IL-13, while T-bet ${ }^{\mathrm{FM}-}$ ILC2 expressed only IL-13. However, T-bet ${ }^{\mathrm{FM}+}$ ILC2 demonstrated only limited co-expression of these cytokines (Figure $2 \mathrm{G}$ ).

\section{T-bet ${ }^{\mathrm{FM}+}$ cLP ILC2 show a distinct genetic profile}

To further characterise $\mathrm{T}-$ bet $^{\mathrm{FM}+}$ and $\mathrm{T}-$ bet $^{\mathrm{FM}-}$ ILC2, differentially expressed transcripts were analysed using FACS purified cLP cells. T-bet ${ }^{\mathrm{FM}+}$ ILC2 shared a gene expression profile with T-bet ${ }^{\mathrm{FM}-}$ ILC2 in relation to ILC2-signature genes, while striking differences were also identified (Figure 3A). The expression of transcripts for the ILC2-related cytokines IL-13, IL-5 and IL-4, was equivalent in T-bet ${ }^{\mathrm{FM}+}$ and T-bet ${ }^{\mathrm{FM}-}$ ILC2, as was expression of amphiregulin (Areg). In addition, both $\mathrm{T}$-bet ${ }^{\mathrm{FM}+}$ and $\mathrm{T}$-bet ${ }^{\mathrm{FM}-}$ ILC2 expressed transcripts for the IL-33 and IL-25 receptors subunits (Il1rl1 (ST2) and Il17rb respectively) and the signature ILC2 surface markers KLGR1 and ICOS. Similarly, the 
transcription factor ROR $\alpha$ was homogeneously expressed in both populations. These results confirm that this $\mathrm{T}-\mathrm{bet}^{\mathrm{FM}+}$ population expresses the core transcriptional profile associated with ILC2. Of note, neither T-bet ${ }^{\mathrm{FM}+}$ nor T-bet ${ }^{\mathrm{FM}-}$ ILC2 expressed genes related to an NK cell- genetic profile (Eomes, Gzmb, Prflor Tnfsf10).

Tbx21 transcripts were not detected in either T-bet ${ }^{\mathrm{FM}-}$ ILC2 or $\mathrm{T}-\mathrm{bet}^{\mathrm{FM}+}$ ILC2, but Tbet $^{\mathrm{FM}+}$ ILC2 expressed Ncrl (encoding NKp46) and the T-bet target gene Ifng. Similarly, the expression of other T-bet related genes, such as Cd226, Illrl and Ill2rb2 was upregulated in T-bet ${ }^{\mathrm{FM}+}$ ILC2. Other genes were also differentially expressed between Tbet $^{\mathrm{FM}+}$ and T-bet ${ }^{\mathrm{FM}-}$ ILC2, including Cxcr6, Cd70, Wsx1, Cd220r, Il17ra, Thyl, Icam or Ccl5, highlighting the differences between these two ILC2 subsets. Therefore, T-bet ${ }^{\mathrm{FM}+}$ ILC2 display a unique transcriptional profile, supporting the hypothesis that T-bet ${ }^{\mathrm{FM}+}$ constitute an ILC subset distinct from ILC2. Hence from hereon, we refer to these cells as ILC1-ILC2.

To further characterize ILC1-ILC2, the expression of candidate surface markers identified by the gene array analysis was assessed on cLP ILC1-ILC2 and ILC2 (Figure 3B-C). Corroborating the gene array data, the ILC1-ILC2 population had greater expression of NKp46 and CD226 (DNAM-1) than conventional cLP ILC2 (Figure 3C). However, not all ILC1-ILC2 expressed NKp46 or high levels of CD226 indicating that these cells are heterogeneous. Both CD226 and NKp46 are known to be expressed by ILC1 and NK cells, and their expression has been correlated with T-bet expression (reviewed by Chiossone et al., 2018). CD226 binds to CD112 and CD155 on transformed cells resulting in NK cell-mediated lysis and IFN- $\gamma$ production from NK cells (Tahora- 
Hanaoka et al., 2004). Likewise, the ligation of NKp46 expressed by NK cell to its ligand results in cytotoxicity and cytokine production (Glasnet et al., 2018, Lakshmikanth et al., 2009, Halfteck et al., 2009). In contrast to CD226 and NKp46, some cLP ILC2 showed surface expression of the IL-27R subunit IL-27R $\alpha$ (Wsx-1), while cLP ILC1-ILC2 did not express this receptor as predicted from the RNA array. IL-27 signalling has been reported to inhibit IL-13 and IL-5 expression by lung ILC2 and Th2 cells (Moro et al., 2016, Stumhofer et al., 2007). In addition, IL-27 has been suggested to induce T-bet in T cells (Hibbert et al., 2003). The absence of surface IL-27R on cLP ILC1-ILC2 indicates that these cells may be regulated differently from conventional cLP ILC2, at least at steady state. Furthermore, ILC1-ILC2 had a lower expression of CD127 in comparison to conventional ILC2 (Figure 3C), and this is in line with previous publications indicating that T-bet restricts CD127 expression in cLP ILC (Garrido Mesa et al., 2019, Powell et $a l .$, 2012). In contrast, surface expression of IL-12RB2, PD-L1 (CD274), ICAM-1, CD122, CD90.2, CXCR6, IL-17RA, CD70, CD200R, CD25, IL-1R1 and CTLA4 was similar between ILC1-ILC2 and ILC2 (Figure 3B).

Tbx $2^{\text {flffl }} \mathrm{Cre}-\mathrm{Ert} 2^{+/-}$(Het) and Tbx $2^{\text {flffl }} \mathrm{Cre}-\mathrm{Ert}^{-{ }^{--}}$(WT) mice were employed to test the post-developmental requirement of T-bet for CD226 ${ }^{\mathrm{Hi}} \mathrm{NKp} 46^{+}$ILC1-ILC2 maintenance. Tamoxifen was injected into these mice each day for a period of 5 days. 3 weeks after the first injection we observed a significant loss of cLP ILC1-ILC2 expressing NKp46 and high levels of CD226 (Figure 3D). This highlights the critical role of T-bet for the maintenance of these cells. 


\section{Functional analysis of cLP ILC1-ILC2}

We have previously shown that T-bet deficiency on a C57BL/6 background drives a more potent immune response to T. spiralis (Alcaide et al., 2007, Garrido Mesa et al., 2019), a phenomenon attributed to enhanced type 2 immunity. Hence we explored whether T-betexpressing ILC, including ILC1-ILC2, may play a functional role in this model in the absence of $\mathrm{T}$ and B cells. However, the worm burden of T. spiralis was not altered in TRnUC mice when compared with T-bet sufficient animals, indicating that lack of T-bet expression in the innate immune system plays no functional role in this model (Supplementary Figure 2A). In addition, ILC1-ILC2 are also unlikely to play any significant role in the immune response to the intestinal helminths $N$. brasiliensis or $H$. polygyrus. For these experiments, the role of T-bet was tested in mice with a germline depletion of T-bet and also in the model of induced depletion of T-bet using Cre-Ert $2^{-/+}$ mice. In none of these models was it possible to record an altered anti-parasite host response in the absence of T-bet. Fecal egg counts or worm burden in the small intestine was not altered upon infection and there were no differences between the mouse models for goblet cell counts as determined by Periodic acid-Schiff (PAS) stain, throughout infection time course (Supplementary Figure 2B-I).

In order to identify a functional role for ILC1-ILC2 we utilised a dextran sulphate sodium (DSS) model of induced colitis in T-bet ${ }^{\mathrm{FM}}$ mice. These mice developed acute colitis 2 days after the withdrawal of DSS (Figure 4A). Although ILC1-ILC2 were potent producers of IFN $\gamma$ and IL-13 in the fresh water control as outlined above, these cytokineproducing cells were significantly diminished in mice with DSS-induced colitis (Figure 4B). This finding indicates that ILC1-ILC2 may play a role in the intestinal immune response in colitis that is distinct from that of ILC1 or ILC2. 


\section{ILC1- ILC2 are unlikely to derive from ILC2 precursors}

The origin of intestinal ILC1- ILC2 could be a separate developmental pathway or the result of active plasticity of ILC. To explore the possibility that ILC1- ILC2 are a separate novel ILC subset, we first analysed these cells in the lamina propria of colons and small intestines of mice at the age of weaning (3 weeks post-partum). ILC1- ILC2 were indeed present in both of these tissues (Figure 5A, Supplementary Figure 3A). These cells did not express $\alpha 4 \beta 7$ indicating they did not migrate into the tissue recently. Furthermore, we could only detect very few T-bet ${ }^{\mathrm{FM}+}$ ILC2p and T-bet ${ }^{\mathrm{FM}+}$ CLP populations in the bone marrow of some, but not all, adult mice (Figure 5B, Supplementary Figure 3B). ILC2p were defined as Lin $^{-} \mathrm{CD} 127^{+} \alpha 4 \beta 7^{\text {hi }}$ Flt3 $3^{-} \mathrm{CD} 25^{+}$while CLP were gated as Lin $^{-} \mathrm{CD} 127^{+}$ $\alpha 4 \beta 7^{-} \mathrm{Flt}^{+} \mathrm{CD} 25^{-}$bone marrow cells. Hence, we sought to determine whether we could generate $\mathrm{T}$-bet ${ }^{\mathrm{FM}+}$ ILC2 from T-bet ${ }^{\mathrm{FM}-}$ CLP or ILC2p in a 6 day culture on OP9-DL1 stromal cells in the presence of rIL-7,rSCF and rIL-33 using an established method to develop ILC2. We were able to generate ILC2 from either source, but it was not possible to detect T-bet ${ }^{\mathrm{FM}+}$ ILC2 in these cultures (Figure 5C, Supplementary Figure 3C). This may indicate that ILC1-ILC2 develop in the periphery or the tissue after extravasation, or from an undefined precursor or pathway. As we were not able to detect T-bet ${ }^{\mathrm{FM}+}$ ILC2p consistently perhaps due to the rarity of these cells, we sorted this population from the pooled bone marrow of multiple animals and cultured them on OP9-DL1 cells. Strikingly, these $\mathrm{T}-$ bet $^{\mathrm{FM}+}$ ILC2p differentiated into T-bet ${ }^{\mathrm{FM}+}$ ILC2 (Supplementary Figure 3D). Hence, it is plausible that T-bet ${ }^{\mathrm{FM}+}$ ILC2p are precursors of ILC1-ILC2. Interestingly, when we analysed ILC1-ILC2 in one-week old litters, we could not detect ILC1- ILC2 in the colonic lamina propria (Figure 5D). $\alpha 4 \beta 7^{-}$ILC2 were present in both colonic and small intestinal lamina propria, however, ILC1- ILC2 could only be found in a 
subpopulation of $\mathrm{KLRG}^{+} \mathrm{ICOS}^{\text {low }}$ ILC2 present in SI LP, but not cLP (Figure 5D-E). These SI LP ILC1-ILC2 expressed $\alpha 4 \beta 7$ indicating that these cells may have emigrated recently from the bone marrow. Therefore, we interrogated an ILC2 specific single cell RNA-seq data set (Ricardo-Gonzalez et al., 2018) and were able to detect T-bet ${ }^{+}$ILC2 in a specific subpopulation of bone marrow cells (Figure 5F, Supplementary Figure 3E-F).

This study is the first report of a novel murine subset of intestinal LP ILC1-ILC2 in vivo. Our data indicate a functional, genetic and protein expression profile of ILC1-ILC2 cells that is distinct from conventional intestinal LP ILC2, ILC1, ILC3 and NK cells. 


\section{METHODS}

\section{Animals}

Rosa $26^{\mathrm{YFP} /+}$ (Jackson labs) mice were sourced commercially and bred with T-bet ${ }^{\text {cre/+ }}$ mice to generate the $\mathrm{T}-\mathrm{bet}{ }^{\mathrm{Cre} /+} \mathrm{x}$ Rosa26 $6^{\mathrm{YFP} /+}\left(\mathrm{T}-\right.$ bet $\left.^{\mathrm{FM}}\right)$ mice. All mice were housed in specific pathogen-free facilities at King's College London Biological Services Unit, London School of Hygiene and Tropical Medicine Biological Service Facility, University of Manchester Biological Services Facility or at Charles River Laboratories. T-bet-AmCyan and ROR $\gamma$ t reporter mice were a gift from Dr Jinfang Zhu (Yu et al., 2015) and Dr Gérard Eberl (Lochner et al., 2011), respectively. C57BL/6 WT (Charles River), T-bet KO, IFN$\gamma \mathrm{KO}$, IL-27R $\alpha \mathrm{KO}$ (Charles River) and Ert2 (Jackson labs) mice were sourced commercially (all C57BL1/6 background). $T$ - $b e^{f l f l}$ mice were previously generated by our group (Gökmen et al., 2013) and crossed with Ert2 mice to generate Cre-Ert2 ${ }^{+/}$(Het) and $C r e-E r t 2^{-/-}(\mathrm{WT})$ mice expressing T-bet flffl . A colony of colitis-free $\operatorname{Rag} 2^{-/-} \times \mathrm{Tbx} 21^{-/-}$ (TRnUC) mice was generated from the TRUC colony that was descendant from the originally described TRUC mice (Powell et al., 2012).

Generation of T-bet ${ }^{\text {cre/+ }}$ mouse.

To allow the expression of the Cre-recombinase under the expression of the T-bet endogenous promoter, a T-bet knock-in mouse was generated (GenOway, France). For this purpose, an IRES-Cre cassette was introduced downstream of the Stop codon of the T-bet gene, in the 3'UTR (Supplementary Figure S1A). The genomic region of interest containing the murine Tbx21 locus was isolated by PCR from 129Sv genetic background. 
PCR fragments were subcloned into the pCR4-TOPO vector (Invitrogen). The genomic clones (containing intron 1 to exon 6) were used to construct the targeting vector. Briefly, a 5.6-kb fragment comprising Tbx21 exon 2 and 6 and a 1.6-kb fragment located downstream of the Tbx21 exon 6 STOP codon were used to flank an IRES-Cre cassette (FRT site-PGK promoter-Neo cDNA-FRT site).

Screening of T-bet-targeted embryonic stem cell clones.

The FseI-linearized targeting vector was transfected into C57BL/6 ES cells. Positive selection was started 48 hours after electroporation, by addition of $200 \mu \mathrm{g} / \mathrm{ml} \mathrm{G} 418$ (150 $\mu \mathrm{g} / \mathrm{ml}$ active component; Life Technologies). Then, 275 resistant clones were isolated, amplified, and screened by PCR and further confirmed by Southern blot.

Generation of chimeric mice and breeding scheme.

One floxed mutated Tbx21 ES cell clone was microinjected into albino C57BL/6 strain (C57BL/6J-Tyrc-2J/J) blastocysts, and gave rise to male chimeras with a significant ES cell contribution (as determined by the percentage of light and dark patches on their coat). After mating with C57BL/6 CMV-Flp-expressing female mice to remove the FRTflanked Neo cassette, offspring were genotyped by PCR and Southern blot to ensure removal of the Neo cassette. PCR and Southern blot screening conditions are available on request. The mosaic excised F1 mouse was them mated with C57BL/6 WT mice to obtain a pure line of Cre-expressing T-bet knock-in mice: T-bet ${ }^{\text {cre/t+ }}$.

\section{Tamoxifen induction of Tbx21 depletion}

A tamoxifen stock solution was prepared by suspending $1 \mathrm{~g}$ of tamoxifen (free base: MP biomedicals, LLC) into $18 \mathrm{ml} 100 \%$ ethanol and heating to $37^{\circ} \mathrm{C}$ briefly to dissolve the 
tamoxifen. Prior to the injections this solution was diluted at 1:4.56 in sunflower oil and heated briefly to $37^{\circ} \mathrm{C}$. In vivo depletion of $\mathrm{T}$-bet was induced by consecutive intraperitoneal injections of tamoxifen on five consecutive days with one injection per day (1mg per injection). Three weeks after the first injection of tamoxifen tissues were harvested or the mice were infected or treated with DSS as outlined below.

\section{Isolation of cells}

cLP, SI LP and cecum LP leukocytes were isolated using a published method (Grohnke et al., 2017). Peyer's patches were removed from SI prior to cell isolation. Briefly, the epithelium was removed by incubation in $\mathrm{HBSS}$ lacking $\mathrm{Mg}^{2+}$ or $\mathrm{Ca}^{2+}$ (Invitrogen) supplemented with EDTA and HEPES. The tissue was further digested in $2 \%$ of foetal calf serum (FCS Gold, PAA Laboratories) supplemented in $0.5 \mathrm{mg} / \mathrm{ml}$ collagenase D, $10 \mu \mathrm{g} / \mathrm{ml}$ DNase I and 1.5mg/ml dispase II (all Roche). The LP lymphocyte-enriched population was harvested from a 40\%-80\% Percoll (GE Healthcare) gradient. Lung leukocytes were cut in small pieces and cells were further isolated by an incubation in 300IU/ ml collagenase II (Gibco) and $3 \mu \mathrm{g} / \mathrm{ml}$ DNase I (Roche) for one hour at 37 degree C. Ear sheets were incubated in $5 \mathrm{mg} / \mathrm{ml}$ collagenase IV (Sigma) for one hour at 37 degree C. Cutaneous leukocytes were further purified by Percoll gradient application. Thymic cells were isolated as described before (Schroeder et al., 2013).

\section{Flow Cytometry}

Flow cytometry was performed using a standard method. For ILC stains a lineage cocktail was used consisting of antibodies specific for CD3, B220, CD19, CD11b, Ter-119, Gr-1, CD5 and FceRI. In case of thymic tissue antibodies specific for CD4 and CD8 were added 
to the lineage mix, and the lineage mix for skin tissue contained anti-CD2 antibodies. For a complete list of the antibodies used see Table 1. Samples were acquired using an LSRFortessa $^{\mathrm{TM}}$ cell analyser (Becton Dickinson, USA), and data were analysed using FlowJo software (Tree Star, USA). A FoxP3 staining kit (Invitrogen) was used for staining CTLA4, cytokines and transcription factors. In case of cytokine analysis, cells were pre-stimulated with $100 \mathrm{ng} / \mathrm{ml}$ PMA and $2 \mu \mathrm{M}$ ionomycin in the presence of $6 \mu \mathrm{M}$ monensin for 3 hours prior to $\mathrm{FACS}$ analysis at $37^{\circ} \mathrm{C} 5 \% \mathrm{CO}_{2}$.

\section{Cell Sorting and in vitro culture}

Single-cell suspensions from the intestine or bone marrow were stained with fluorescently labelled antibodies and sorted (purity > 98\%) using a BD FACSAria III cell sorter (BD Biosciences). For ILC, antibodies against CD45, lineage markers and IL-7R $\alpha$ and DAPI stain were used to separate live CD45 $\mathrm{Lin}^{-} \mathrm{IL}-7 \mathrm{R}^{+}$cells. cLP Rag2 ${ }^{-/-}$ILC2 (ICOS $^{+}$ $\mathrm{KLRG}^{+}$) were cultured in DMEM supplemented with 10\% FCS, 1xGlutaMax (Gibco), $50 \mathrm{U} / \mathrm{ml}$ penicillin, $50 \mu \mathrm{g} / \mathrm{ml}$ streptomycin, $10 \mathrm{mM}$ HEPES, 1x non-essential amino acids (Gibco), $1 \mathrm{mM}$ sodium pyruvate and $50 \mu \mathrm{M} \beta$-mercaptoethanol (Gibco). The medium was further supplemented with rmIL-7 and rhIL-2 (both at $10 \mu \mathrm{g} / \mathrm{ml}$ ) and further cytokines as indicated (all cytokines were used at a final concentration of $10 \mu \mathrm{g} / \mathrm{ml}$ ). Cells were harvested and analysed by flow cytometry after 3 days in culture at $37^{\circ} \mathrm{C}$ $5 \% \mathrm{CO}_{2}$.

\section{ILC generation in OP9-DL1 system}

CLP or ILC2p were seeded on OP9-DL1 to generate ILC2 using an established method (Seehus et al., 2016). Briefly, 7,500 cells were co-cultured with mitomycin pre-treated 
OP9-DL1 in presence of rmIL-7, rmSCF and rmIL-33 (all $20 \mathrm{ng} / \mathrm{ml}$ ) for 6 days prior to FACS analysis.

\section{Gene expression array}

RNA was extracted using Trizol reagent (Invitrogen, UK), according to the manufacturer's protocol and contaminating DNA was removed with the RNase-Free DNase Set (Qiagen, UK).

cDNA was synthetized using Ovation One-Direct System and labelled using Encore BiotinIL module (Nugen, USA) following the manufacture's protocol. RNA and cDNA quantity and quality were assessed using the Agilent RNA 6000 Nano Kit and Agilent RNA 6000 Pico Kit according to the manufacture's protocol (Agilent Technologies, USA). Labelled cDNA were hybridised on a MouseWG-6 v2.0 Expression BeadChip (Illumina, USA) and gene expression analysis was performed using Partek software (Partek Incorporated, USA). All raw and processed gene expression array data are available at Gene Expression Omnibus (www.ncbi.nlm.nih.gov/geo/).

\section{Infection mouse models}

Mice were infected with $T$. spiralis, $N$. brasiliensis or $H$. polygyrus using published methods (Turner et al., 2013, Entwisle et al., 2017, Garrido Mesa et al., 2019). In some experiments T-bet depletion was induced prior to infection with $N$. brasiliensis or $H$. polygyrus. 


\section{DSS-induced colitis}

Colitis was induced by adding 3\% DSS (36-50 KDa, MP Biomedicals, Ontario, USA) to the drinking water for 5 days. Non-colitic mice were administered sterile drinking water. Mice were sacrificed 7 days after the beginning of the experiment. Weight and clinical abnormalities were monitored on a daily basis.

\section{Single-cell RNA-seq analysis}

Raw expression matrices were obtained from GEO (GSE117567, Ricardo-Gonzalez et al. 2018), then processed using Seurat 3.0 (Stuart et al 2019). Genes detected in less than 5 cells, and cells with less than 500 detected genes, were removed. Following normalization (using NormalizeData), samples were merged into a single object, and the top 2000 variable genes were used to calculate the PCA $(\mathrm{PCs}=30)$, then UMAP $(\operatorname{dims}=20)$ reductions. Shared nearest neighbour and clustering were carried out using FindNeighbours (reduction $=$ PCA, dims $=20)$ and FindClusters $($ res $=0.5)$ respectively.

\section{Statistics}

Results are expressed as mean \pm SEM. Data were analysed using Student's t-test or MannWhitney U test, as appropriate, using GraphPad Prism 5.0 (GraphPad Inc., USA). ns: nonsignificant; $* \mathrm{p}<0.05 ; * * \mathrm{p}<0.01 ; * * * \mathrm{p}<0.001 ; * * * * \mathrm{p}<0.0001$. 


\section{Study approval}

All animal experiments were performed in accredited facilities in accordance with the

UK Animals (Scientific Procedures) Act 1986 (Home Office Licence Numbers PPL:

70/6792, 70/8127, 70/7869 and 60/4423 ). 


\section{ACKNOWLEDGMENTS}

We thank the members of the LORD laboratory for valuable discussions and critically commenting on the manuscript. In addition, we thank the BRC flow cytometry core team for technical help, and acknowledge financial support from the Department of Health via the NIHR comprehensive Biomedical Research Centre award to Guy's and St. Thomas' NHS Foundation Trust in partnership with King's College London and King's College Hospital NHS Foundation Trust. We also thank Professor Zúñiga-Pflücker (Sunnybrook Research Institute, University of Toronto) for contributing OP9-DL1 cells and Dr Jinfang Zhu (National Institute of Allergy and Infectious Diseases, USA) for providing T-betAmCyan mice.

\section{AUTHOR CONTRIBUTIONS}

Study concept and design (JHS, NG, RGJ, PL, JKH, HH, RKG, JFN, GML), acquisition of data (JHS, NG, TZ, ALG, LC, ES, LBR, JWL, JFN), data analysis and interpretation (JHS, NG, PL, GB, LBR, JWL, JFN, GML), technical support (AI, CMH, RR), obtained funding (NG, JFN, JKH, GML), drafting of manuscript (JHS), study supervision (JFN, GML).

\section{DISCLOSURE}

The authors have no conflict of interest to declare. 


\section{REFERENCES}

Affinass N, Zhang H, Löhning M, Hartmann S, Rausch S. 2018. Manipulation of the balance between Th2 and Th2/1 hybrid cells affects parasite nematode fitness in mice. Eur J Immunol. 48(12):1958-1964.

Alcaide P, Jones TG, Lord GM, Glimcher LH, Hallgren J, Arinobu Y, Akashi K, Paterson AM, Gurish MA, Luscinskas FW. 2007. Dendritic cell expression of the transcription factor T-bet regulates mast cell progenitor homing to mucosal tissue. J Exp Med. 204(2):431-9.

Bal SM, Bernink JH, Nagasawa M, Groot J, Shikhagaie MM, Golebski K, van Drunen CM, Lutter R, Jonkers RE, Hombrink P, Bruchard M, Villaudy J, Munneke JM, Fokkens W, Erjefält JS, Spits H, Ros XR 2016. IL-1 $\beta$, IL-4 and IL-12 control the fate of group 2 innate lymphoid cells in human airway inflammation in the lungs. Nat Immunol. 17(6):636-45.

Bredo G, Storie J, Shrestha Palikhe N, Davidson C, Adams A, Vliagoftis H, Cameron L. 2015. Interleukin-25 initiates Th2 differentiation of human CD4(+) T cells and influences expression of its own receptor. Immun Inflamm Dis. 15;3(4):455-68.

Chiossone L, Dumas PY, Vienne M, Vivier E. 2018. Natural killer cells and other innate lymphoid cells in cancer. Nat Rev Immunol. 18(11):671-688. 
Entwistle LJ, Wilson MS. 2017. MicroRNA-mediated regulation of immune responses to intestinal helminth infections. Parasite Immunol. 2017. 39(2).

Evans CM , Jenner RG 2013. Transcription factor interplay in T helper cell differentiation Brief Funct Genomics. 12(6):499-511.

Jenner RG, Townsend MJ, Jackson I, Sun K, Bouwman RD, Young RA, Glimcher LH, Lord GM. 2009. The transcription factors T-bet and GATA-3 control alternative pathways of T-cell differentiation through a shared set of target genes. Proc Natl Acad Sci U S A. 106(42):17876-81.

Garrido-Mesa N, Schroeder JH, Stolarczyk E, Gallagher AL, Lo JW, Bailey C, Campbell L, Sexl V, MacDonald TT, Howard JK, Grencis RK, Powell N, Lord GM 2019. T-bet controls intestinal mucosa immune responses via repression of type 2 innate lymphoid cell function. Mucosal Immunol. 12(1):51-63.

Glasner A, Levi A, Enk J, Isaacson B, Viukov S, Orlanski S, Scope A, Neuman T, Enk CD, Hanna JH, Sexl V, Jonjic S, Seliger B, Zitvogel L, Mandelboim O. 2018. NKp46 Receptor-Mediated Interferon- $\gamma$ Production by Natural Killer Cells Increases Fibronectin 1 to Alter Tumor Architecture and Control Metastasis. Immunity. 48(1):107-119.

Golebski K, Ros XR, Nagasawa M, van Tol S, Heesters BA, Aglmous H, Kradolfer CMA, Shikhagaie MM, Seys S, Hellings PW, van Drunen CM, Fokkens WJ, Spits H, Bal SM. 2019. IL-1 $\beta$, IL-23, and TGF- $\beta$ drive plasticity of human ILC2s towards IL-17-producing ILCs in nasal inflammation. Nat Commun. 10(1):2162. 
Gökmen MR, Dong R, Kanhere A, Powell N, Perucha E, Jackson I, Howard JK, Hernandez-Fuentes M, Jenner RG, Lord GM. 2013. Genome-wide regulatory analysis reveals that T-bet controls Th17 lineage differentiation through direct suppression of IRF4. J Immunol. 191(12):5925-32.

Gronke K, Kofoed-Nielsen M, Diefenbach A. 2017. Isolation and Flow Cytometry Analysis of Innate Lymphoid Cells from the Intestinal Lamina Propria. Methods Mol Biol. 1559:255-265.

Gury-BenAri M, Thaiss CA, Serafini N, Winter DR, Giladi A, Lara-Astiaso D, Levy M, Salame TM, Weiner A, David E, Shapiro H, Dori-Bachash M, Pevsner-Fischer M, Lorenzo-Vivas E, Keren-Shaul H, Paul F, Harmelin A, Eberl G, Itzkovitz S, Tanay A, Di Santo JP, Elinav E, Amit I 2016. The Spectrum and Regulatory Landscape of Intestinal Innate Lymphoid Cells Are Shaped by the Microbiome. Cell. 166(5):1231-1246

Halfteck GG, Elboim M, Gur C, Achdout H, Ghadially H, Mandelboim O. 2009. Enhanced in vivo growth of lymphoma tumors in the absence of the NK-activating receptor NKp46/NCR1. J Immunol. 182(4):2221-30.

Hibbert L, Pflanz S, De Waal Malefyt R, Kastelein RA. 2003. IL-27 and IFN-alpha signal via Stat1 and Stat 3 and induce T-Bet and IL-12Rbeta2 in naive T cells. J Interferon Cytokine Res. 23(9):513-22. 
Huang Y, Guo L, Qiu J, Chen X, Hu-Li J, Siebenlist U, Williamson PR, Urban JF Jr, Paul WE. 2015. IL-25-responsive, lineage-negative KLRG1(hi) cells are multipotential 'inflammatory' type 2 innate lymphoid cells. Nat Immunol. 16(2):161-9.

Klose CSN, Artis D. 2020. Innate lymphoid cells control signaling circuits to regulate tissue-specific immunity. Cell Res. 30(6):475-491.

Lakshmikanth T, Burke S, Ali TH, Kimpfler S, Ursini F, Ruggeri L, Capanni M, Umansky V, Paschen A, Sucker A, Pende D, Groh V, Biassoni R, Höglund P, Kato M, Shibuya K, Schadendorf D, Anichini A, Ferrone S, Velardi A, Kärre K, Shibuya A, Carbone E, Colucci F. 2009. NCRs and DNAM-1 mediate NK cell recognition and lysis of human and mouse melanoma cell lines in vitro and in vivo J. Clin. Invest., 119, pp. $1251-1263$

Lim AI, Menegatti S, Bustamante J, Le Bourhis L, Allez M, Rogge L, Casanova JL, Yssel H, Di Santo JP. 2016. IL-12 drives functional plasticity of human group 2 innate lymphoid cells. J Exp Med. 213(4):569-83.

Lim AI, Li Y, Lopez-Lastra S, Stadhouders R, Paul F, Casrouge A, Serafini N, Puel A, Bustamante J, Surace L, Masse-Ranson G, David E, Strick-Marchand H, Le Bourhis L, Cocchi R, Topazio D, Graziano P, Muscarella LA, Rogge L, Norel X, Sallenave JM, Allez M, Graf T, Hendriks RW, Casanova JL, Amit I, Yssel H, Di Santo JP. 2017. Systemic Human ILC Precursors Provide a Substrate for Tissue ILC Differentiation. 168(6):1086-1100.e10. 
Lochner M, Ohnmacht C, Presley L, Bruhns P, Si-Tahar M, Sawa S, Eberl G. J. 2011. Microbiota-induced tertiary lymphoid tissues aggravate inflammatory disease in the absence of RORgamma t and LTi cells. Exp Med. 208(1):125-34.

Macias-Ceja DC, Ortiz-Masiá D, Salvador P, Gisbert-Ferrándiz L, Hernández C, Hausmann M, Rogler G, Esplugues JV, Hinojosa J, Alós R, Navarro F, Cosin-Roger J, Calatayud S, Barrachina MD. 2019. Succinate receptor mediates intestinal inflammation and fibrosis. Mucosal Immunol. 12(1):178-187.

McKenzie ANJ, Spits H, Eberl G. 2014. Innate lymphoid cells in inflammation and immunity. Immunity. 41(3):366-374.

Moro K, Kabata H, Tanabe M, Koga S, Takeno N, Mochizuki M, Fukunaga K, Asano K, Betsuyaku T, Koyasu S. 2016. Interferon and IL-27 antagonize the function of group 2 innate lymphoid cells and type 2 innate immune responses.

Nat Immunol. 17(1):76-86.

Mosmann TR, Coffman RL. 1989. TH1 and TH2 cells: different patterns of lymphokine secretion lead to different functional properties. Annu Rev Immunol. 7:145-73.

Ohne Y, Silver JS, Thompson-Snipes L, Collet MA, Blanck JP, Cantarel BL, Copenhaver AM, Humbles AA, Liu YJ. 2016. IL-1 is a critical regulator of group 2 innate lymphoid cell function and plasticity. Nat Immunol. 17(6):646-55. 
Oliphant CJ, Hwang YY, Walker JA, Salimi M, Wong SH, Brewer JM, Englezakis A, Barlow JL, Hams E, Scanlon ST, Ogg GS, Fallon PG, McKenzie AN. 2014. MHCIImediated dialog between group 2 innate lymphoid cells and CD4(+) T cells potentiates type 2 immunity and promotes parasitic helminth expulsion. Immunity. 21;41(2):283-95

Peine M, Rausch S, Helmstetter C, Fröhlich A, Hegazy AN, Kühl AA, Grevelding CG, Höfer T, Hartmann S, Löhning M. 2013. Stable T-bet(+)GATA-3(+) Th1/Th2 hybrid cells arise in vivo, can develop directly from naive precursors, and limit immunopathologic inflammation. PLoS Biol. 11(8):e1001633.

Powell N, Walker AW, Stolarczyk E, Canavan JB, Gökmen MR, Marks E, Jackson I, Hashim A, Curtis MA, Jenner RG, Howard JK, Parkhill J, MacDonald TT, Lord GM. 2012. The transcription factor T-bet regulates intestinal inflammation mediated by interleukin-7 receptor+ innate lymphoid cells. Immunity. 37(4):674-84.

Ricardo-Gonzalez RR, Van Dyken SJ, Schneider C, Lee J, Nussbaum JC, Liang HE, Vaka D, Eckalbar WL, Molofsky AB, Erle DJ, Locksley RM. (2018) Tissue signals imprint ILC2 identity with anticipatory function. 2018. Nat Immunol. 19(10):1093-1099.

Schroeder JH, Bell LS, Janas ML, Turner M. 2013. Pharmacological inhibition of glycogen synthase kinase 3 regulates T cell development in vitro. PLoS One. 8(3):e58501

Seehus C, Kaye J. 2016. In vitro Differentiation of Murine Innate Lymphoid Cells from Common Lymphoid Progenitor Cells. Bio Protoc. 6(6):e1770. 
Silver JS, Kearley J, Copenhaver AM, Sanden C, Mori M, Yu L, Pritchard GH, Berlin AA, Hunter CA, Bowler R, Erjefalt JS, Kolbeck R, Humbles AA. 2016. Inflammatory triggers associated with exacerbations of COPD orchestrate plasticity of group 2 innate lymphoid cells in the lungs. Nat Immunol. 17(6):626-35.

Srinivas S, Watanabe T, Lin CS, William CM, Tanabe Y, Jessell TM, Costantini F. 2001. Cre reporter strains produced by targeted insertion of EYFP and ECFP into the ROSA26 locus. BMC Dev Biol.1:4.

Stuart T, Butler A, Hoffman P, Hafemeister C, Papalexi E, Mauck WM 3rd, Hao Y, Stoeckius M, Smibert P, Satija R. 2019. Comprehensive Integration of Single-Cell Data, Cell, Volume 177, Issue 7, 1888 - 1902.

Stumhofer JS, Silver JS, Laurence A, Porrett PM, Harris TH, Turka LA, Ernst M, Saris CJ, O'Shea JJ, Hunter CA. 2007. Interleukins 27 and 6 induce STAT3-mediated T cell production of interleukin 10. Nat Immunol. 8(12):1363-71

Tahara-Hanaoka S, Shibuya K, Onoda Y, Zhang H, Yamazaki S, Miyamoto A, Honda S, Lanier LL, Shibuya A. 2004. Functional characterization of DNAM-1 (CD226) interaction with its ligands PVR (CD155) and nectin-2 (PRR-2/CD112). Int Immunol. 16(4):533-8.

Turner JE, Morrison PJ, Wilhelm C, Wilson M, Ahlfors H, Renauld JC, Panzer U, Helmby H, Stockinger B. 2013. IL-9-mediated survival of type 2 innate lymphoid cells 
promotes damage control in helminth-induced lung inflammation. J Exp Med 210(13):2951-65.

Vivier E, Artis D, Colonna M, Diefenbach A, Di Santo JP, Eberl G, Koyasu S, Locksley RM, McKenzie ANJ, Mebius RE, Powrie F, Spits H. 2018. Innate Lymphoid Cells: 10 Years On. Cell. 174(5):1054-1066.

Xu W, Cherrier DE, Chea S, Vosshenrich C, Serafini N, Petit M, Liu P, Golub R, Di Santo JP. 2019. An Id2 ${ }^{\text {RFP }}$-Reporter Mouse Redefines Innate Lymphoid Cell Precursor Potentials. Immunity. 50(4):1054-1068.

Yu X, Pappu R, Ramirez-Carrozzi V, Ota N, Caplazi P, Zhang J, Yan D, Xu M, Lee WP, Grogan JL. 2014. TNF superfamily member TL1A elicits type 2 innate lymphoid cells at mucosal barriers. Mucosal Immunol. 7(3):730-40.

Yu F, Sharma S, Edwards J, Feigenbaum L, Zhu J. 2015. Dynamic expression of transcription factors T-bet and GATA-3 by regulatory $\mathrm{T}$ cells maintains immunotolerance. Nat Immunol. 16(2):197-206.

Zhang K, Xu X, Pasha MA, Siebel CW, Costello A, Haczku A, MacNamara K, Liang T, Zhu J, Bhandoola A, Maillard I, Yang Q. 2017. Cutting Edge: Notch Signaling Promotes the Plasticity of Group-2 Innate Lymphoid Cells. J Immunol. 198(5):1798-1803. 


\section{FIGURE LEGENDS}

Figure 1. ILC2-like cells expressing NKp46 and T-bet exists in the intestinal lamina propria

ILC were isolated from the intestinal lamina propria for FACS analysis. (a) ILC were gated as live $\mathrm{CD} 45^{+} \mathrm{Lin}^{-} \mathrm{CD} 127^{+}$leukocytes. (b) Expression of ROR $\gamma \mathrm{t}-\mathrm{GFP}$ and surface NKp46 in live CD45 ${ }^{+}$Lin $^{-} \mathrm{CD}_{127^{+}} \mathrm{ICOS}^{+} \mathrm{KLRG}^{+}$cLP ILC. Surface expression of NKp46, ICOS and ST2 in live $\mathrm{CD}^{+} 5^{+} \mathrm{Lin}^{-} \mathrm{CD} 127^{+} \mathrm{ICOS}^{+} \mathrm{KLRG}^{+}$cLP ILC in (c) C57BL/6, T-bet KO and IFN $\gamma$ KO mice (e) C57BL/6 and IL-27R $\alpha$ KO mice and (g) Rag and TrnUC mice, and (d, f, h) statistical analysis of NKp46 ${ }^{+} \mathrm{KLRG}^{+} \mathrm{cLP}$ ILC presence in these mice. Data shown are representative of a minimum of 3 biological replicates.

Figure 2. A subset of ILC2 expresses T-bet.

ILC were isolated from various tissues for FACS analysis. (a) Surface expression of Tbet-AmCyan and ST2 in live $\mathrm{CD}_{4} 5^{+} \mathrm{Lin}^{-} \mathrm{CD} 127^{+} \mathrm{ICOS}^{+} \mathrm{KLRG}^{+}$cLP ILC in T-bet reporter mice. (b) T-bet fate mapper and GATA3 expression in live CD45 ${ }^{+} \mathrm{Lin}^{-} \mathrm{CD} 127^{+}$ $\mathrm{ICOS}^{+} \mathrm{KLRG}^{+}$cLP, cecum LP and SI LP ILC2 in T-bet ${ }^{\mathrm{FM}}$ mice. (c) T-bet fate mapper, ST2 and KLRG1 expression in live $\mathrm{CD}^{2} 5^{+} \mathrm{Lin}^{-} \mathrm{CD}_{127^{+}} \mathrm{ICOS}^{+} \mathrm{CD} 25^{+}$pulmonary, cutaneous and thymic ILC2 in T-bet ${ }^{\mathrm{FM}}$ mice. (d) Summary plot for Figure 2a,b and c to show percentage of T-bet ${ }^{+}$ILC2. (e,f) Rag2 $2^{-/-}$cLP ILC2 were sorted as live CD45 ${ }^{+}$in $^{-}$ $\mathrm{CD}_{127^{+}} \mathrm{ICOS}^{+} \mathrm{KLRG}^{+}$and cultured in vitro for 3 days in the presence of IL-7 and IL2. Cytokines indicated were also added to the medium, and T-bet and NKp46 expression in live $\mathrm{CD}^{4} 5^{+} \mathrm{Lin}^{-} \mathrm{CD} 90.2^{+} \mathrm{ICOS}^{+} \mathrm{KLRG}^{+} \mathrm{ILC}$ was examined by FACS analysis after 3 days in culture and (f) percentage of T-bet expressing ILC2 are shown. (g) IL-13 and 
IFN $\gamma$ expression and co-expression in live $\mathrm{CD} 45^{+} \mathrm{Lin}^{-} \mathrm{CD} 127^{+} \mathrm{KLRG}^{+} \mathrm{ICOS}^{+} \mathrm{T}^{- \text {bet }^{\mathrm{FM}}+}$ ILC was examined by FACS analysis. Data shown are representative of a minimum of 3 biological replicates.

Figure 3. ILC1-ILC2 show a distinct genetic profile and dependent on T-bet T-bet $^{\mathrm{FM}+}$ and T-bet ${ }^{\mathrm{FM}-}$ cLP ILC2 were FACS sorted to perform a genetic profiling. (a) Volcano plot comparing the fold change in gene expression in T-bet ${ }^{\mathrm{FM}+}$ and $\mathrm{T}-$ bet $^{\mathrm{FM}-}$ cLP ILC2 isolated from T-bet ${ }^{\mathrm{FM}}$ mice. A heat map shows the expression of selected genes in T-bet ${ }^{\mathrm{FM}+}$ and T-bet ${ }^{\mathrm{FM}-}$ cLP ILC2. cLP ILC2 from T-bet ${ }^{\mathrm{FM}}$ mice were isolated for FACS analysis. (b) IL-12RB, PD-L1 (CD274), ICAM-1, CD122, CD90.2, CXCR6, IL-17RA, CD70, CTLA4, IL-1R1 and CD200R expression in live CD45 ${ }^{+}$Lin $^{-}$CD127 ${ }^{+} \mathrm{ICOS}^{+}$ KLRG1 $^{+}$T-bet $^{\mathrm{FM}}$ cLP ILC. (c) NKp46, CD226, IL-27R $\alpha$ and CD127 expression in live $\mathrm{CD}^{+} 5^{+} \mathrm{Lin}^{-} \mathrm{CD} 127^{+} \mathrm{ICOS}^{+} \mathrm{KLRG}^{+} \mathrm{T}^{- \text {bet }^{\mathrm{FM}}}{ }^{\mathrm{cLP}}$ ILC. (d) CD226, NKp46 and IL-27R $\alpha$ expression on live $\mathrm{CD}_{4} 5^{+} \mathrm{Lin}^{-} \mathrm{CD} 127^{+} \mathrm{ICOS}^{+} \mathrm{KLRG}^{+}$cLP ILC from tamoxifen pretreated WT and Het Cre-Ert2-T-bet ${ }^{\mathrm{fl} / \mathrm{fl}}$ mice were analysed by FACS. Data shown are representative of a minimum of 3 biological replicates.

Figure 4: ILC-ILC2 produce less IFN $\gamma$ and IL-13 during DSS-induced colitis T-bet $^{\mathrm{FM}}$ mice were treated with $3 \%$ DSS in the drinking water for 5 days, and cLP ILC were harvested for FACS analysis after another 2 days. Control mice received fresh water (FW) at the same time. (a) Analysis of body weight loss in mice receiving DSS or fresh water is demonstrated. (b) Percentage of IL-13 and IFN $\gamma$ expressing live CD $45^{+}$Lin $^{-}$ $\mathrm{CD}_{127^{+}} \mathrm{KLRG}^{+} \mathrm{ICOS}^{+} \mathrm{T}$-bet ${ }^{\mathrm{FM}}$ ILC was examined by FACS analysis. Data shown are plotted from 4 biological replicates. 
Figure 5. ILC1-ILC2 do not derive from a T-bet ${ }^{\mathrm{FM}-}$ ILC2p.

ILC were examined by FACS analysis. (a) T-bet fate mapper expression and $\alpha 4 \beta 7$ expression in live $\mathrm{CD}_{4} 5^{+} \mathrm{Lin}^{-} \mathrm{CD} 127^{+} \mathrm{ICOS}^{+} \mathrm{KLRG}^{+}{ }^{+} \mathrm{T}^{-b e t}{ }^{\mathrm{FM}}$ cLP and SI LP ILC in 3 weeks old T-bet ${ }^{\mathrm{FM}}$ mice. (b) T-bet fate mapper expression in live CD45 ${ }^{+} \mathrm{Lin}^{-} \mathrm{CD} 127^{+}$ $\alpha 4 \beta 7^{+} \mathrm{CD} 25^{+}$bone marrow ILC2p and live $\mathrm{CD} 45^{+} \mathrm{Lin}^{-} \mathrm{CD} 127^{+} \mathrm{Flt}^{+}$bone marrow CLP in T-bet FM mice. (c) Generation of live CD45 ${ }^{+}$Lin $^{-} \mathrm{CD} 90.2^{+} \mathrm{ICOS}^{+} \mathrm{KLRG} 1^{+} \mathrm{ILC}$ from T-bet $^{\mathrm{FM}-}$ CLP or T-bet ${ }^{\mathrm{FM}-}$ ILC2p in an OP9-DL1 co-culture system. T-bet fate mapper expression in live $\mathrm{CD}_{4} 5^{+} \mathrm{Lin}^{-} \mathrm{CD} 127^{+} \mathrm{ICOS}^{+} \mathrm{KLRG}^{+}$is presented. (d) cLP and (e) SI LP ILC in one-week old T-bet ${ }^{\mathrm{FM}}$ mice. Data shown are representative of a minimum of 3 biological replicates (a-c) or shows one sample pooled from tissues of 7 mice (d-e). (f) A published ILC2-specific single cell RNA-seq dataset (Ricardo-Gonzalez et al., 2018) was used to identify T-bet-expressing ILC2 in multiple organs. A cluster map showing the prevalence of T-bet ${ }^{+}$ILC2 in various organs is shown.

Supplementary Figure 1. Design and evaluation of T-bet fate mapper mouse cLP ILC were isolated for FACS analysis. (a) See method section for further details on the design. (b) $\mathrm{T}-\mathrm{bet} \mathrm{F}^{\mathrm{FM}}$ and T-bet expression in live $\mathrm{CD} 45^{+} \mathrm{Lin}^{-} \mathrm{CD} 127^{+} \mathrm{NKp} 46^{+} \mathrm{NK} 1.1^{+}$ cLP ILC. (c) T-bet ${ }^{\mathrm{FM}}$ expression in live CD $45^{+} \mathrm{Lin}^{-} \mathrm{CD} 127^{+} \mathrm{NKp} 46^{+} \mathrm{CCR} 6^{-}$and $\mathrm{NKp}^{-} 6^{-}$ $\mathrm{CCR6}^{+}$cLP ILC. Data shown are representative of a minimum of 3 biological replicates.

Supplementary Figure 2. Intestinal parasite infection in in the absence of T-bet

(a) Rag and TRnUC mice were infected with T. spiralis for infection analysis. Worm counts in the muscles at day 9 post infection are shown. (b, d) C57BL/6 and T-bet KO or 
(c, e) tamoxifen pre-treated WT and Het Cre-Ert2-T-bet ${ }^{\mathrm{fl} / \mathrm{fl}}$ mice were infected with $N$. brasiliensis for infection analysis. (b, c) PAS-stained histology sections of infected SI tissue and goblet cell numbers per vili and are shown. (d, e) Feces egg counts of $N$. brasiliensis at day 5, 6, 7, 8 and 9 post infection and SI worm count of $N$. brasiliensis at day 7 and 9 post infection are presented. (f, h) C57BL/6 and T-bet KO or (g, i) tamoxifen pre-treated WT and Het Cre-Ert2-T-bet ${ }^{\mathrm{fl} / \mathrm{fl}}$ mice were infected with H. polygyrus for infection analysis. (f, g) PAS-stained histology sections of infected SI tissue and goblet cell numbers and are shown. (h, i) Feces egg counts of $H$. polygyrus at day 14 post infection and SI worm count of $H$. polygyrus at day 14 post infection are presented. Data shown are plotted from a minimum of 3 biological replicates.

Supplementary Figure 3. T-bet-positive ILC2 can be predominately detected in the bone marrow.

Summary plots for (a) Figure 5a, (b) Figure 5b and (c) Figure 5c to demonstrate T-bet expression. (d) FACS analysis of live CD45 ${ }^{+}$Lin $^{-}$CD $90.2^{+} \mathrm{ICOS}^{+} \mathrm{KLRG}^{+}$ILC generated from T-bet ${ }^{\mathrm{FM}-}$ and $\mathrm{T}-\mathrm{bet}^{\mathrm{FM}+}$ ILC2p in an OP9-DL1 co-culture system. T-bet fate mapper expression in live $\mathrm{CD}_{4} 5^{+} \mathrm{Lin}^{-} \mathrm{CD} 127^{+} \mathrm{ICOS}^{+} \mathrm{KLRG}^{+}$is shown. Data shown are derived from BM cells pooled from nine mice. (e,f) A published ILC2-specific single cell RNA-seq dataset (Ricardo-Gonzalez et al., 2018) was used to identify T-betexpressing ILC2 in multiple organs. A distinct genetic profile of BM T-bet ${ }^{+}$ILC2 is illustrated by comparing to the average expression levels of specific markers in ILC2 from all other organs. 
bioRxiv preprint doi: https://doi.org/10.1101/2020.08.21.261073; this version posted August 22, 2020. The copyright holder for this preprint (which was not certified by peer review) is the author/funder. All rights reserved. No reuse allowed without permission. 


\begin{tabular}{|c|c|c|}
\hline Antibody & Clone & Company \\
\hline CD3 & $17 \mathrm{~A} 2$ & eBioscience \\
\hline CD5 & $53-7.3$ & eBioscience \\
\hline CD19 & 1D3 & eBioscience \\
\hline B220 & RA3-6B2 & eBioscience \\
\hline $\mathrm{CD} 11 \mathrm{~b}$ & $\mathrm{M} 1 / 70$ & eBioscience \\
\hline Gr-1 & RB6-8C5 & eBioscience \\
\hline Ter119 & TER-119 & eBioscience \\
\hline FceRI & MAR & eBioscience \\
\hline CD127 & A7R34 & eBioscience \\
\hline NKp46 & $29 \mathrm{~A} 1.4$ & eBioscience \\
\hline ST2 & RMST2-33 & eBioscience \\
\hline ICOS & C398.4 & eBioscience \\
\hline KLRG1 & $2 \mathrm{~F} 1$ & eBioscience \\
\hline CCR6 & 29-2L17 & eBioscience \\
\hline GATA3 & L50-823 & $\mathrm{BD}$ \\
\hline NK1.1 & PK136 & Biolegend \\
\hline IL-13 & eBio13A & eBioscience \\
\hline IFN $\gamma$ & XMG1.2 & eBioscience \\
\hline T-bet & $4 \mathrm{~B} 10$ & Invitrogen \\
\hline CD45 & 30-F11 & Invitrogen \\
\hline$\alpha 4 \beta 7$ & DATK32 & eBioscience \\
\hline CD70 & FR70 & Biolegend \\
\hline IL-12RB2 & 305719 & $\mathrm{R} \& \mathrm{D}$ \\
\hline IL-1R1 & JAMA-147 & eBioscience \\
\hline ICAM-1 & YN1/1.7.4 & eBioscience \\
\hline Flt3 & $\mathrm{A} 2 \mathrm{~F} 10$ & eBioscience \\
\hline CXCR6 & DANID2 & Invitrogen \\
\hline CD200R & OX110 & eBioscience \\
\hline $\mathrm{CD} 25$ & PC61.5 & eBioscience \\
\hline CD90.2 & $30-\mathrm{H} 12$ & $\mathrm{BD}$ \\
\hline IL-17RA & PAJ-17R & eBioscience \\
\hline CD122 & TM- $\beta 1$ & eBioscience \\
\hline PD-L1 & MIH5 & eBioscience \\
\hline CTLA4 & UC10-4B9 & Invitrogen \\
\hline IL-17Ra & 2918 & $\mathrm{BD}$ \\
\hline CD226 & $10 \mathrm{E} 5$ & eBioscience \\
\hline $\mathrm{CD} 2$ & RM2-5 & eBioscience \\
\hline
\end{tabular}


bioRxiv preprint doi: https://doi.org/10.1101/2020.08.21.261073; this version posted August 22, 2020. The copyright holder for this preprint (which was not certified by peer review) is the author/funder. All rights reserved. No reuse allowed without permission.

\begin{tabular}{|l|c|c|} 
CD4 & RM4-5 & eBioscience \\
\hline CD8 & $53-6.7$ & eBioscience \\
\hline
\end{tabular}

Table 1: Antibody clones and distributors 
Figure 1

A

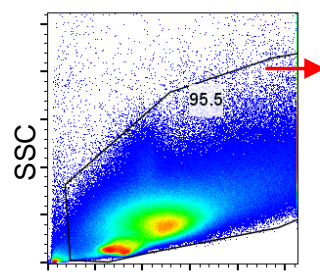

FSC-A

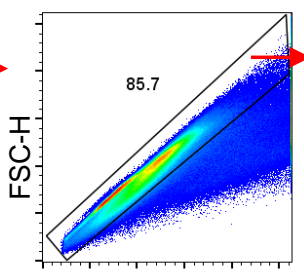

FSC-A

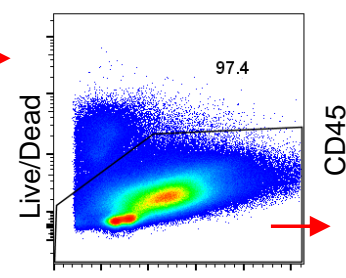

FSC-A

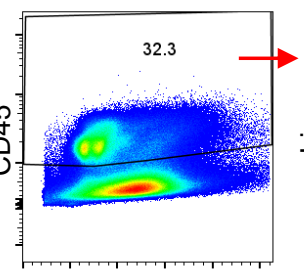

FSC-A

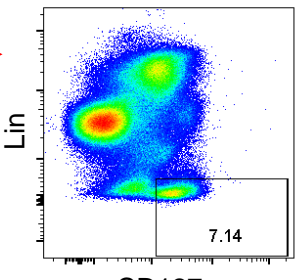

CD127
B
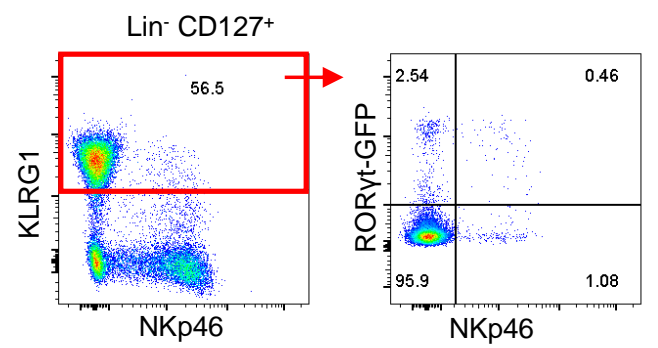

D

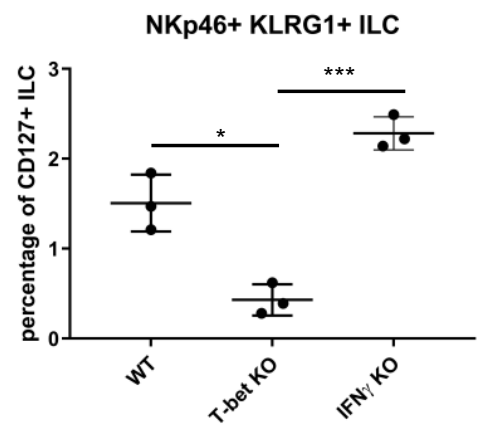

E

WT

G

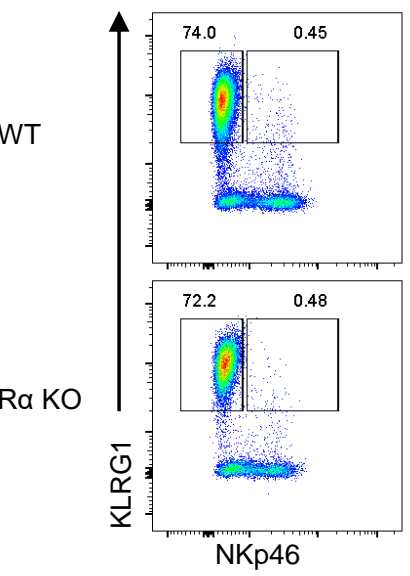

C
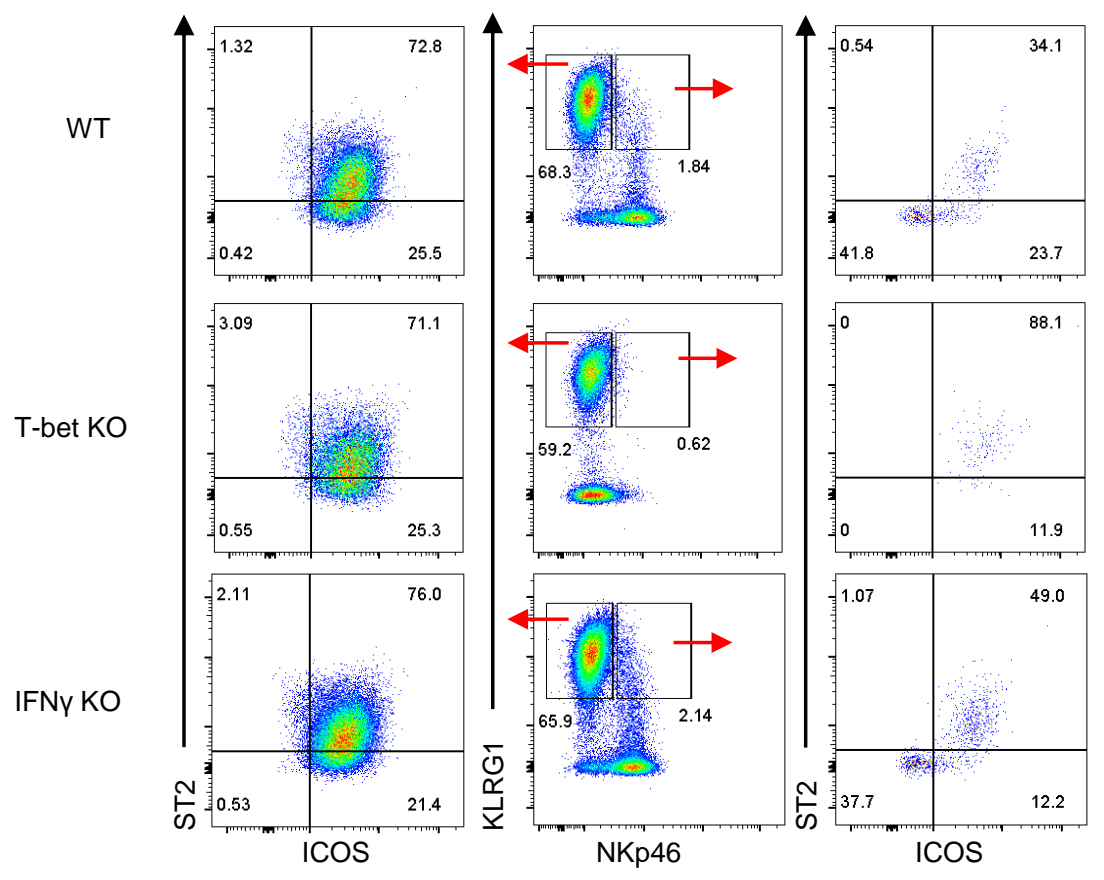

NKp46+ KLRG1+ ILC

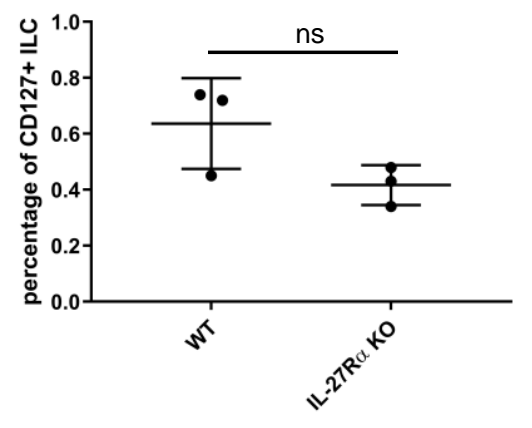

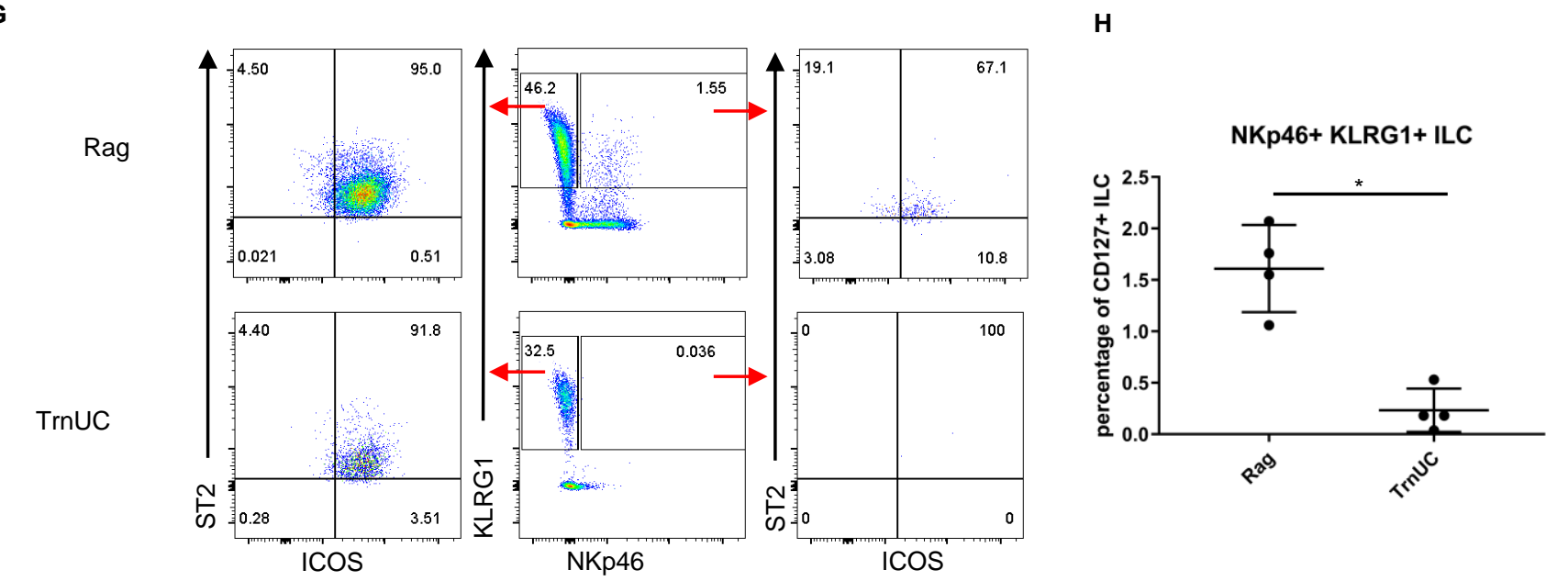


Figure 2

A

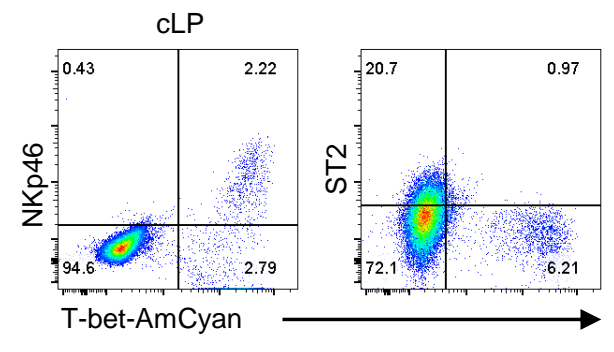

C

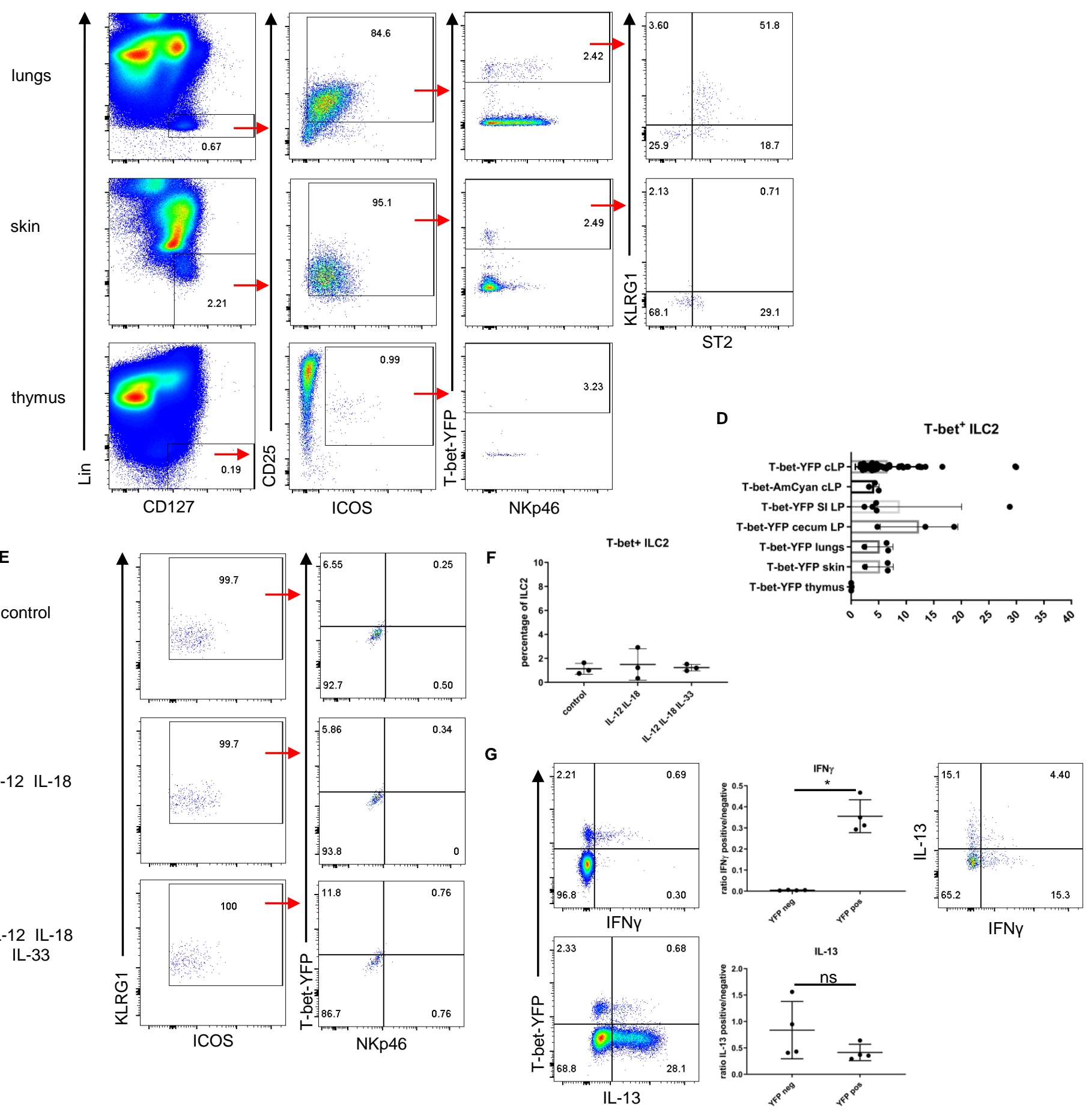

B

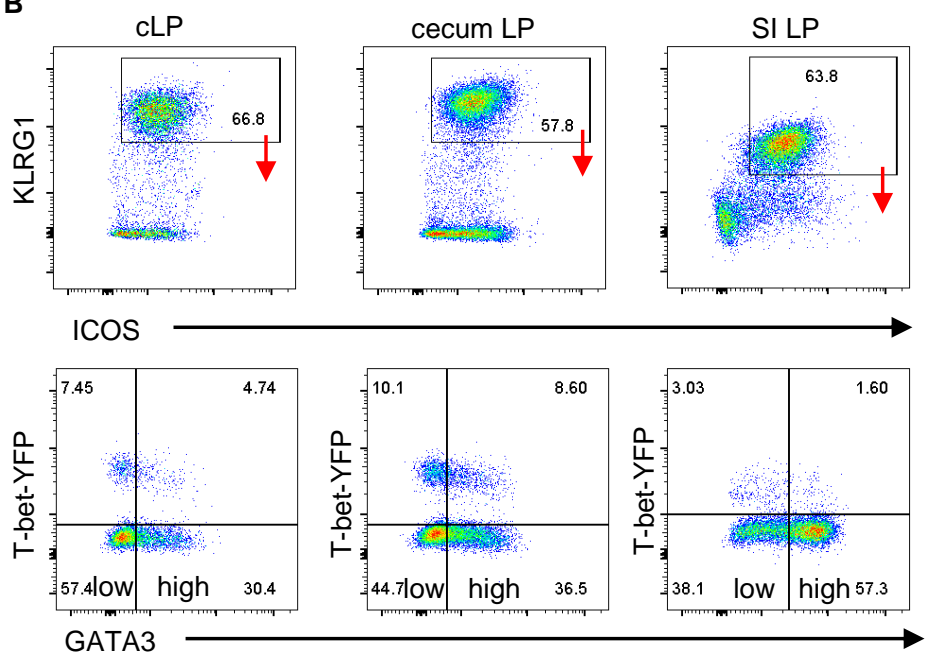


Figure 3

A
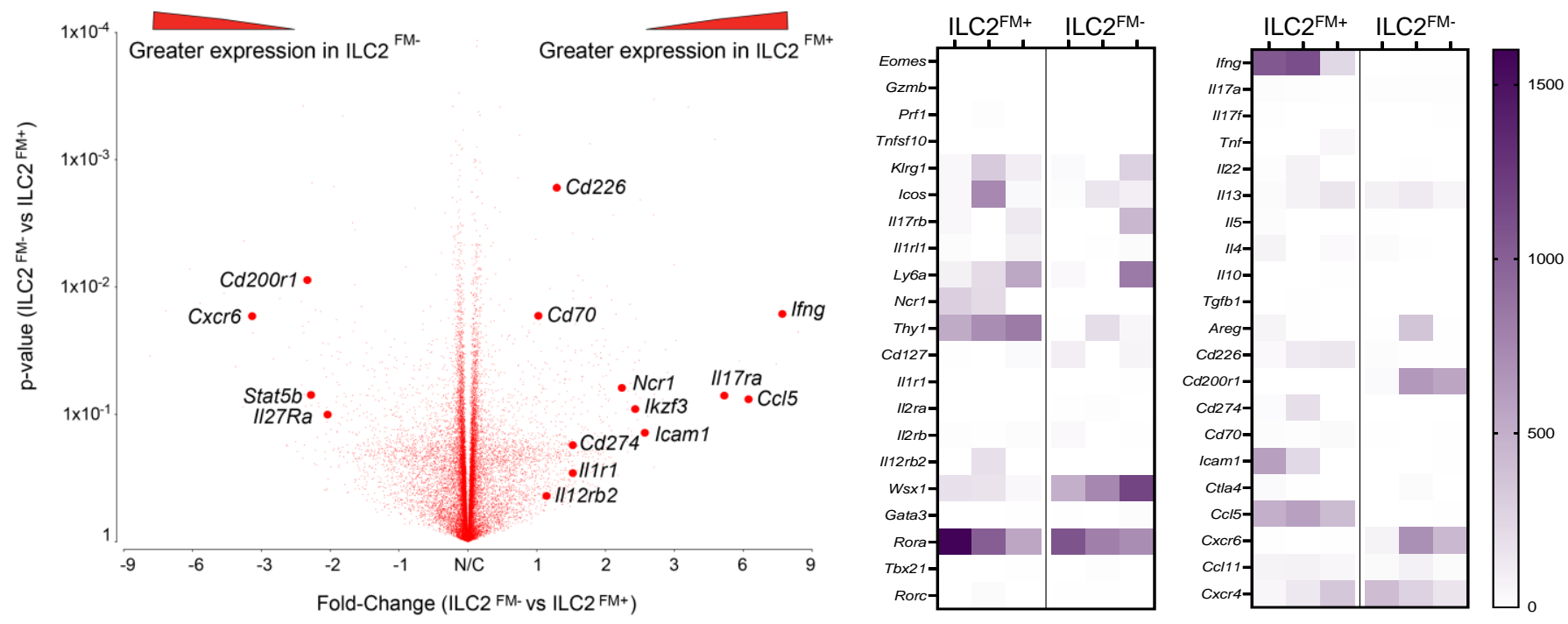

B
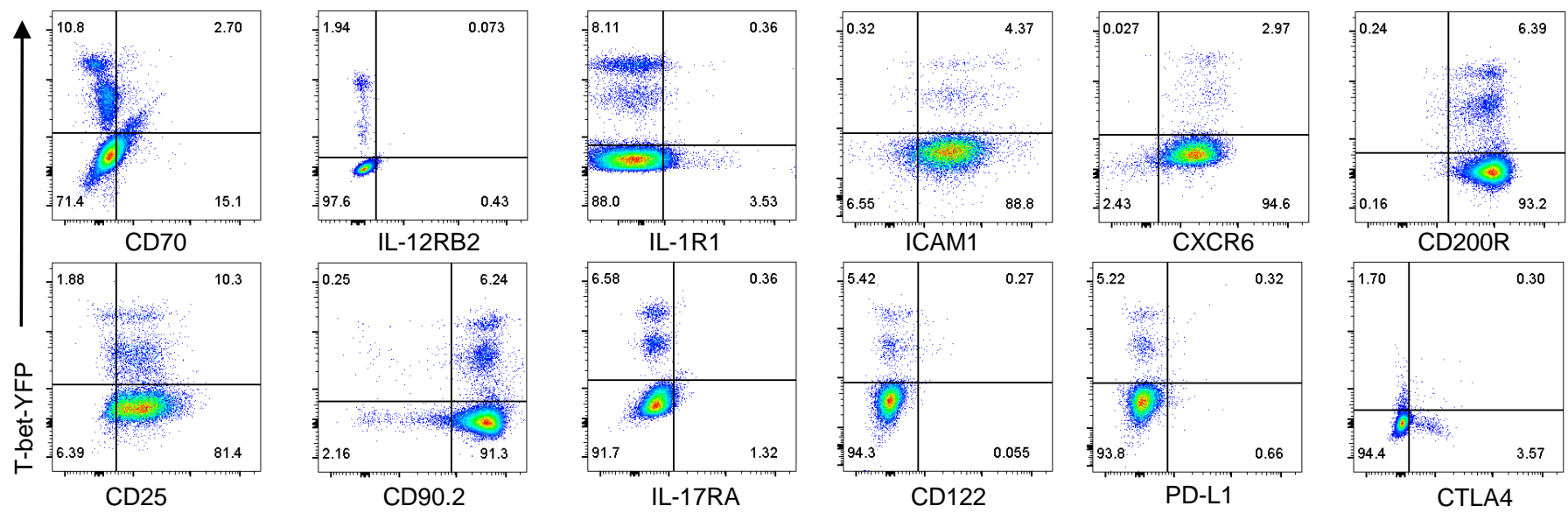

C

D
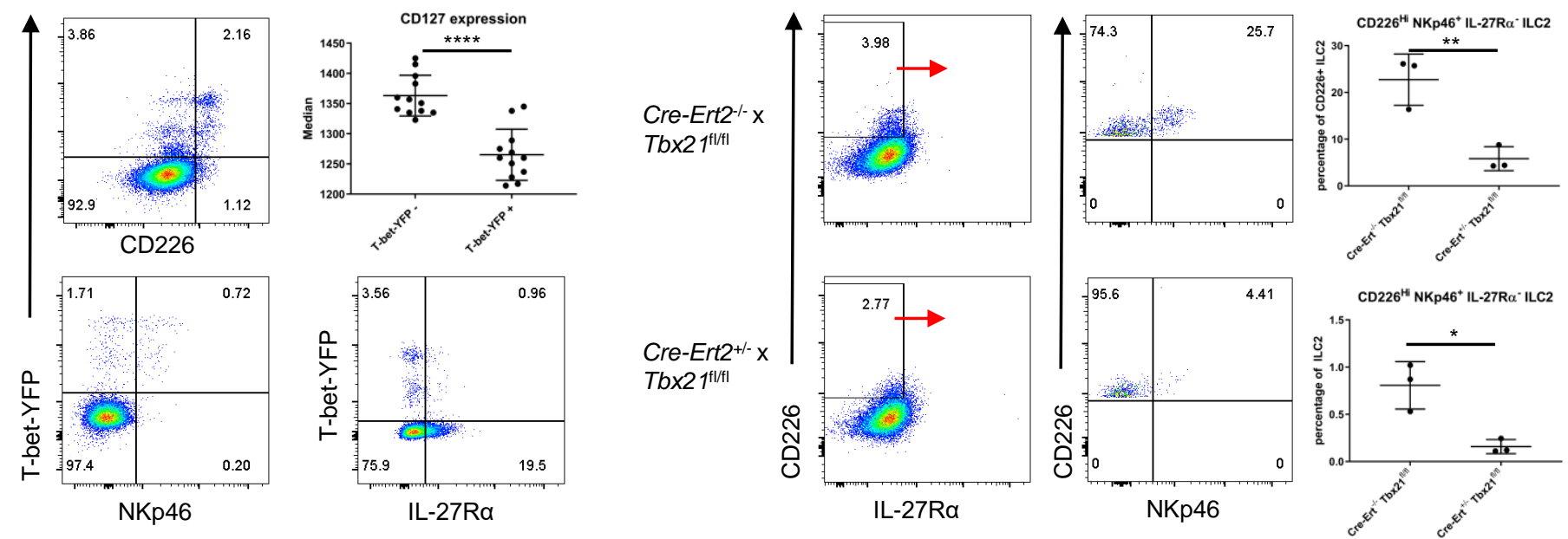
Figure 4

A

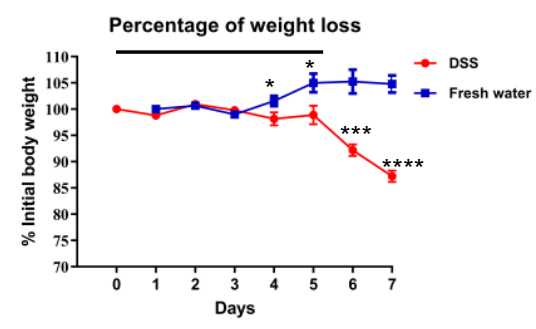

B

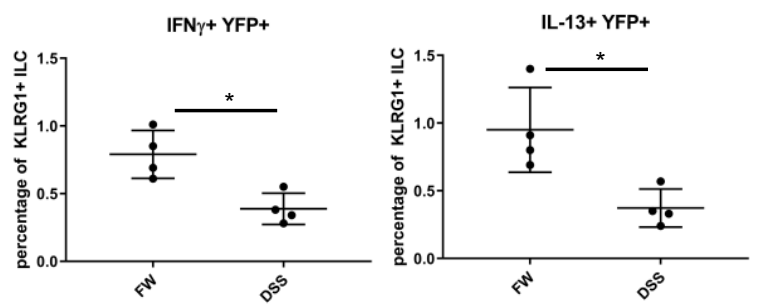


A cLP SI LP
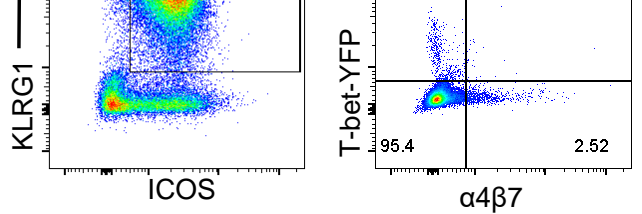

C

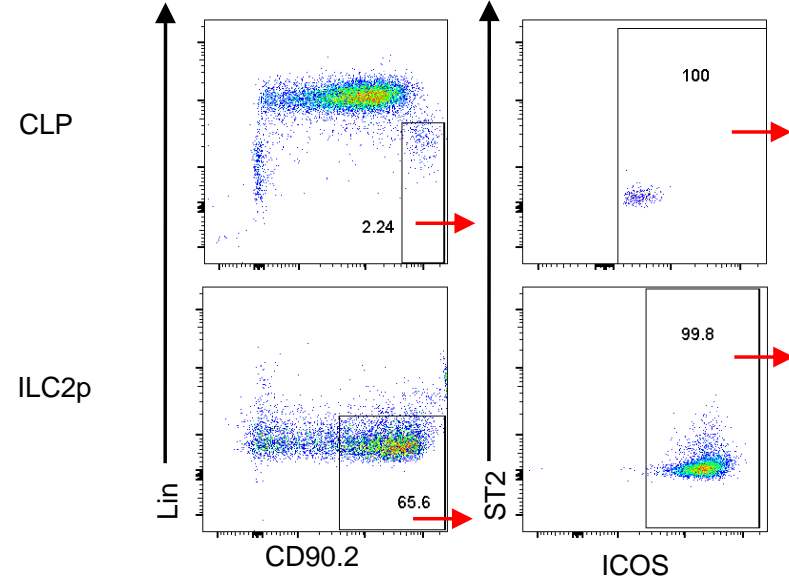

D
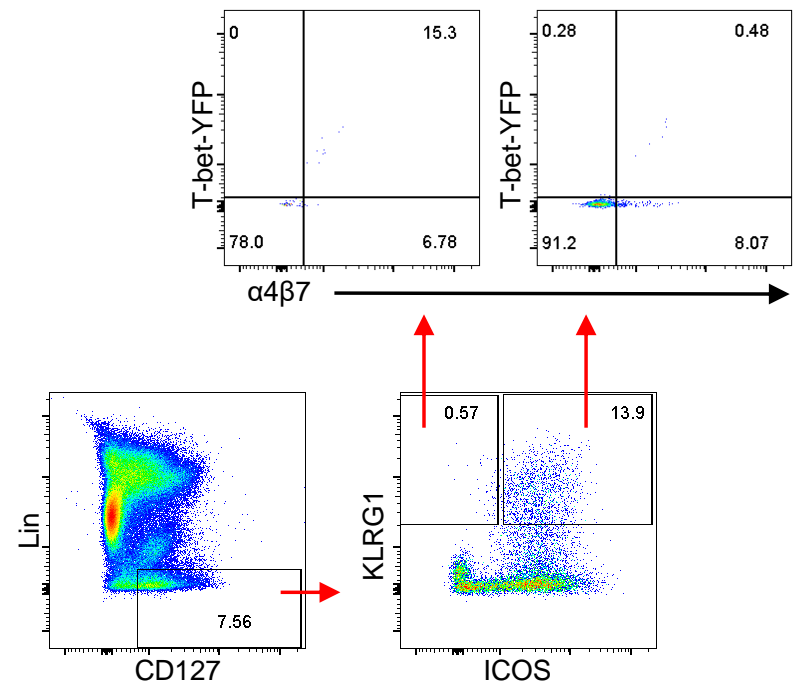

B
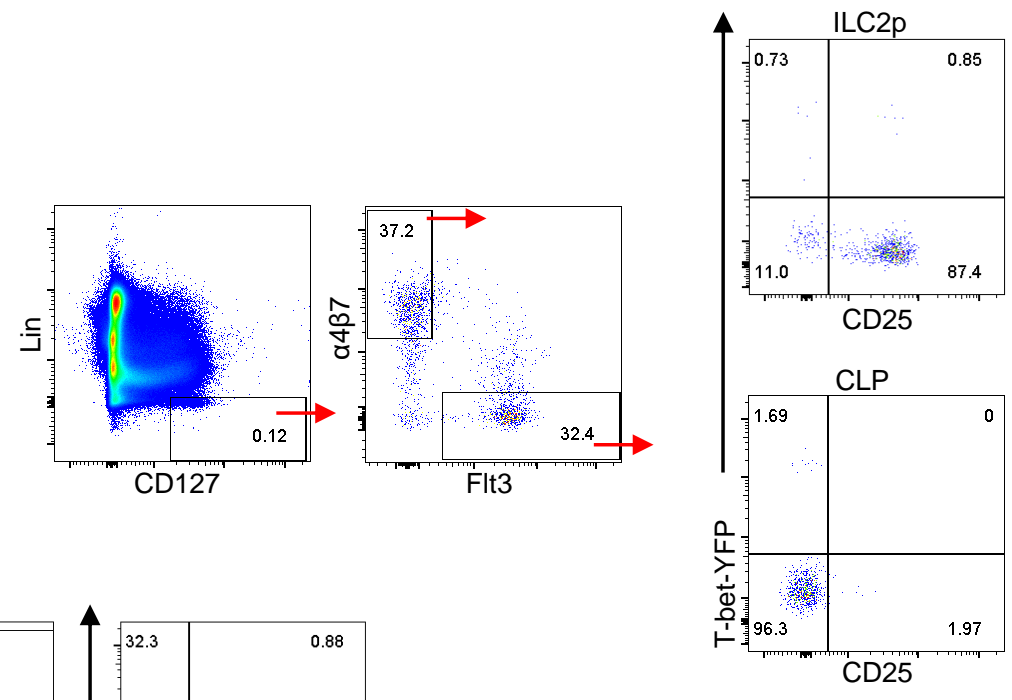

F
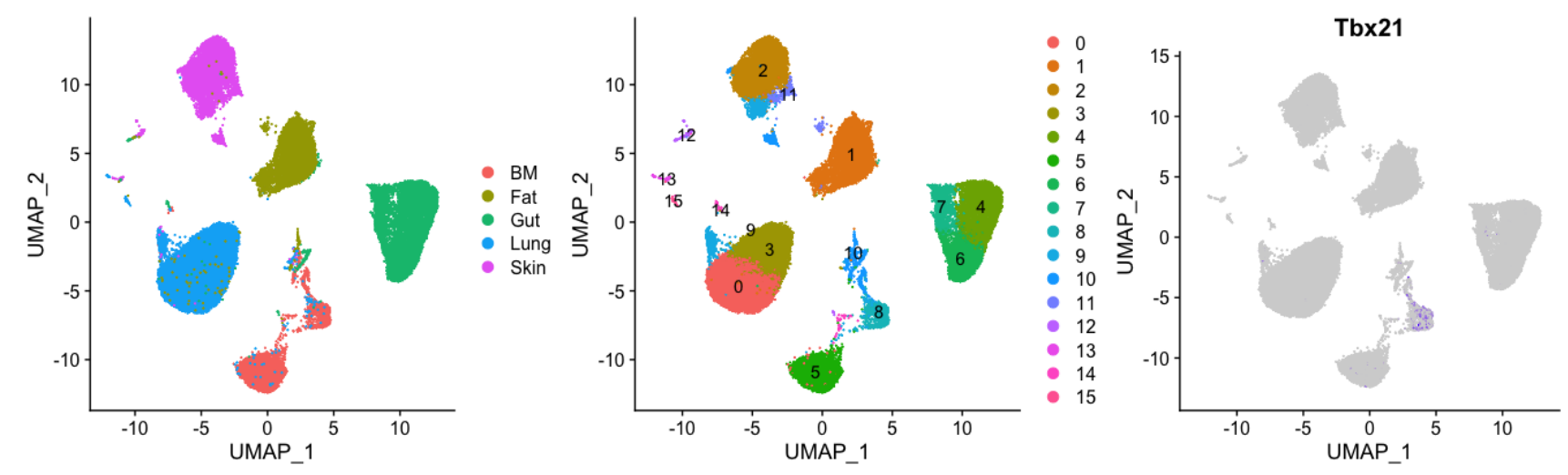

T-bet-YFP

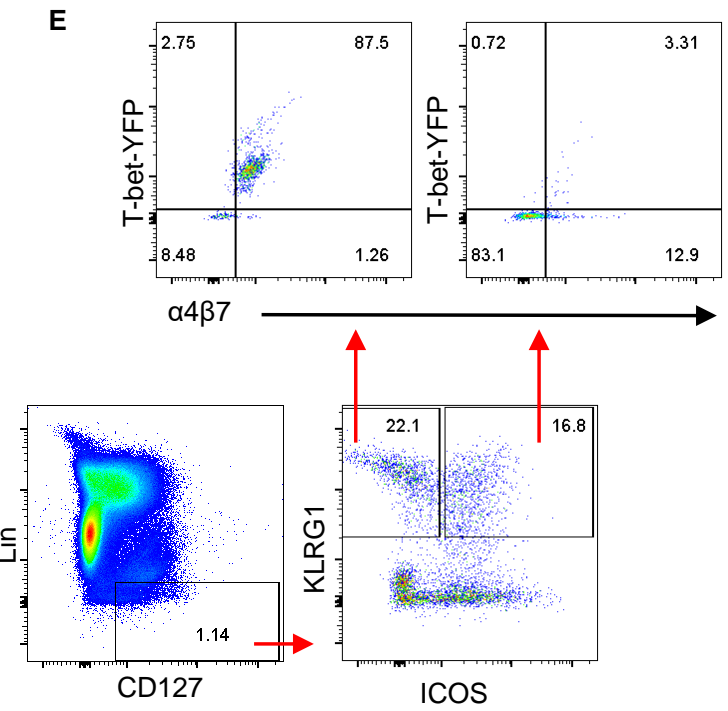

